\title{
The Nonradiative Effect Dominates Local Surface Temperature Change Caused by Afforestation in China
}

\author{
JUN GE \\ Institute for Climate and Global Change Research, School of Atmospheric Sciences, Nanjing University, \\ Nanjing, China, and Australian Research Council Centre of Excellence for Climate Extremes and \\ Climate Change Research Centre, University of New South Wales, Sydney, Australia \\ WEIDONG GUO \\ Institute for Climate and Global Change Research, School of Atmospheric Sciences, and Joint International \\ Research Laboratory of Atmospheric and Earth System Sciences, Nanjing University, Nanjing, China

\section{Andrew J. Pitman And Martin G. De Kauwe} \\ Australian Research Council Centre of Excellence for Climate Extremes and Climate Change Research \\ Centre, University of New South Wales, Sydney, Australia

\section{Xuelong CHEN ${ }^{\mathrm{a}}$} \\ Key Laboratory of Tibetan Environment Changes and Land Surface Processes, Institute of Tibetan Plateau \\ Research, Chinese Academy of Sciences, Beijing, China

\section{CONGBIN Fu} \\ Institute for Climate and Global Change Research, School of Atmospheric Sciences, and Joint International \\ Research Laboratory of Atmospheric and Earth System Sciences, Nanjing University, Nanjing, China
}

(Manuscript received 11 November 2018, in final form 18 April 2019)

\begin{abstract}
China is several decades into large-scale afforestation programs to help address significant ecological and environmental degradation, with further afforestation planned for the future. However, the biophysical impact of afforestation on local surface temperature remains poorly understood, particularly in midlatitude regions where the importance of the radiative effect driven by albedo and the nonradiative effect driven by energy partitioning is uncertain. To examine this issue, we investigated the local impact of afforestation by comparing adjacent forest and open land pixels using satellite observations between 2001 and 2012. We attributed local surface temperature change between adjacent forest and open land to radiative and nonradiative effects over China based on the Intrinsic Biophysical Mechanism (IBM) method. Our results reveal that forest causes warming of $0.23^{\circ} \mathrm{C}$ $\left( \pm 0.21^{\circ} \mathrm{C}\right)$ through the radiative effect and cooling of $-0.74^{\circ} \mathrm{C}\left( \pm 0.50^{\circ} \mathrm{C}\right)$ through the nonradiative effect on local surface temperature compared with open land. The nonradiative effect explains about $79 \%( \pm 16 \%)$ of local surface temperature change between adjacent forest and open land. The contribution of the nonradiative effect varies with forest and open land types. The largest cooling is achieved by replacing grasslands or rain-fed croplands with evergreen tree types. Conversely, converting irrigated croplands to deciduous broadleaf forest leads to warming. This provides new guidance on afforestation strategies, including how these should be informed by local conditions to avoid amplifying climate-related warming.
\end{abstract}

\footnotetext{
${ }^{a}$ Additional affiliation: Chinese Academy of Sciences Center for Excellence in Tibetan Plateau Earth Sciences, Chinese Academy of Sciences, Beijing, China.
}

Corresponding author: Jun Ge, junge@smail.nju.edu.cn 


\section{Introduction}

Afforestation is one mitigation strategy that has been proposed to help efforts to limit global warming to $2^{\circ} \mathrm{C}$ above preindustrial levels, as trees are long-lived stores of carbon (Canadell and Raupach 2008; Jackson et al. 2008; Pacala and Socolow 2004). However, afforestation also affects local and regional climate through biophysical processes (Anderson et al. 2011; Bonan 2008; Bright et al. 2015). For example, forests tend to have lower albedo than grasslands and croplands, which can cause warming of local temperature following afforestation (the radiative effect). Forests also tend to have larger leaf area index, deeper roots, and higher aerodynamic roughness length, which promote evapotranspiration and cooling of local temperature (the nonradiative effect). The balance of the radiative and nonradiative effects explains whether afforestation would reduce or amplify cooling benefits associated with the removal of atmospheric $\mathrm{CO}_{2}$ following afforestation.

Evidence from both observations (Alkama and Cescatti 2016; Duveiller et al. 2018; Lee et al. 2011; Li et al. 2015) and models (Arora and Montenegro 2011; Bala et al. 2007; Davin and de Noblet-Ducoudré 2010; Devaraju et al. 2018) suggests that the radiative effect of afforestation dominates at high latitudes and the nonradiative effect is more important in the tropics. In temperate regions, the radiative and nonradiative effects tend to counterbalance (Perugini et al. 2017). Climate models (Arora and Montenegro 2011; Bala et al. 2007; Davin and de Noblet-Ducoudré 2010) simulate a warming effect while observations (Alkama and Cescatti 2016; Burakowski et al. 2018; Duveiller et al. 2018; Li et al. 2015; Schultz et al. 2017; Wang et al. 2018) point to cooling. Recent studies also suggest afforestation can impact temperature extremes (Findell et al. 2017; Skinner et al. 2018; Teuling et al. 2010) although modeling of these processes is very uncertain (Avila et al. 2012; Li et al. 2018; Pitman et al. 2012). Despite these uncertainties, the biophysical effects of afforestation on climate need to be considered, especially at local and regional scales where afforestation strategies are being implemented, to avoid risk of maladaptation (Anderson et al. 2011; Bonan 2008).

To separate the radiative and nonradiative effects of land use and land cover change (LULCC), extensive studies (e.g., Davin and de Noblet-Ducoudré 2010; Juang et al. 2007; Lee et al. 2011; Luyssaert et al. 2014) have been carried out in the past decade. These studies can be basically divided into two categories based on the method utilized. One group uses sensitivity experiments based on climate models (Davin and de NobletDucoudré 2010). For example, using a fully coupled global climate model, Davin and de Noblet-Ducoudré
(2010) quantified the radiative and nonradiative effects of global deforestation via sensitivity experiments examining parameters associated with albedo, roughness, and evapotranspiration efficiency. A second group uses a decomposition of the surface energy balance equation based on observations from adjacent in situ sites with different land covers (e.g., Juang et al. 2007; Lee et al. 2011; Luyssaert et al. 2014). For example, the Intrinsic Biophysical Mechanism (IBM) method (Lee et al. 2011) attributes local surface temperature change to a radiative forcing term associated with changes in albedo, and an energy redistribution term associated with changes in both the surface aerodynamic resistance and the partitioning of sensible and latent heat fluxes. An advantage of the IBM method lies in a distinction between external forcing and internal feedback (Lee et al. 2011). Thus, the IBM method is efficiently applicable to the separation of the radiative and nonradiative processes caused by afforestation or deforestation. However, both methods have apparent limitations. The in situ observations are geographically restricted, while climate models are subjected to uncertainties in the implementation of land cover change, the representation of crop phenology, and the parameterization of albedo and evapotranspiration (Pitman et al. 2009). Recently, satellite observations have been widely used to investigate the impact of LULCC on local surface temperature (Duveiller et al. 2018; Li et al. 2015; Peng et al. 2014). Bright et al. (2017) further utilized satellite observations to quantify the radiative and nonradiative effects of historical LULCC globally filling the gap between in situ observations and model simulations.

To address growing environmental and ecological concerns associated with rapid economic growth, the Chinese government has initiated a series of national afforestation programs including the Three-North Shelterbelt Development Program, the Natural Forest Conservation Program, and the Grain for Green Program (Bryan et al. 2018; Fu et al. 2017; Liu et al. 2008). Benefiting from these afforestation programs, China has exhibited a world-leading greening trend in the past few decades (Hua et al. 2017; Liu et al. 2015; Piao et al. 2015; Chen et al. 2019). However, the radiative and nonradiative effects of afforestation over China remains uncertain, although the local cooling effect of afforestation has been widely demonstrated by modeling (Ma et al. 2013), in situ observations (Wang et al. 2018), and satellite observations (Ma et al. 2017; Peng et al. 2014). Very few studies attributed the afforestation-induced local surface temperature change to the radiative and nonradiative effects over China, although we note that Wang et al. (2018) did examine this issue using a pair of sites over northern China. Bright et al. (2017) 
TABLE 1. Information for IGBP classes.

\begin{tabular}{|c|c|c|}
\hline Class & Class name & Description \\
\hline 1 & Evergreen needleleaf forests (ENF) & $\begin{array}{l}\text { Lands dominated by needleleaf woody vegetation with a percent cover }>60 \% \\
\text { and height exceeding } 2 \mathrm{~m} \text {. Almost all trees remain green all year. Canopy is } \\
\text { never without green foliage. }\end{array}$ \\
\hline 2 & Evergreen broadleaf forests $(\mathrm{EBF})$ & $\begin{array}{l}\text { Lands dominated by broadleaf woody vegetation with a percent cover }>60 \% \text { and } \\
\text { height exceeding } 2 \mathrm{~m} \text {. Almost all trees and shrubs remain green year round. } \\
\text { Canopy is never without green foliage. }\end{array}$ \\
\hline 3 & Deciduous needleleaf forests (DNF) & $\begin{array}{l}\text { Lands dominated by woody vegetation with a percent cover }>60 \% \text { and height } \\
\text { exceeding } 2 \mathrm{~m} \text {. Consists of seasonal needleleaf tree communities with an } \\
\text { annual cycle of leaf-on and leaf-off periods. }\end{array}$ \\
\hline 4 & Deciduous broadleaf forests (DBF) & $\begin{array}{l}\text { Lands dominated by woody vegetation with a percent cover }>60 \% \text { and height } \\
\text { exceeding } 2 \mathrm{~m} \text {. Consists of broadleaf tree communities with an annual cycle of } \\
\text { leaf-on and leaf-off periods. }\end{array}$ \\
\hline 5 & Mixed forests (MF) & $\begin{array}{l}\text { Lands dominated by trees with a percent cover }>60 \% \text { and height exceeding } 2 \mathrm{~m} \text {. } \\
\text { Consists of tree communities with interspersed mixtures or mosaics of the } \\
\text { other four forest types. None of the forest types exceeds } 60 \% \text { of landscape. }\end{array}$ \\
\hline 10 & Grasslands (GRA) & Lands with herbaceous types of cover. Tree and shrub cover is less than $10 \%$. \\
\hline 12 & Croplands (CRO) & $\begin{array}{l}\text { Lands covered with temporary crops followed by harvest and a bare soil period } \\
\text { (e.g., single and multiple cropping systems). Note that perennial woody crops } \\
\text { will be classified as the appropriate forest or shrub land cover type. }\end{array}$ \\
\hline
\end{tabular}

investigated the radiative and nonradiative effects as a result of LULCC globally, while they performed less analysis on the local impact of afforestation in China. Here we choose to focus on China and tackle the radiative and nonradiative effects of afforestation at more local scale.

Our study aims to attribute afforestation-induced local surface temperature change to the radiative and nonradiative effects over mainland China. This is crucial in understanding the local biophysical effects of historical and future afforestation in this midlatitude country, where large uncertainties remain. To this end, we first examine the local impact of afforestation using satellite observations by "trading space for time," that is, pairing adjacent forest and open land pixels. We then applied the IBM method to each paired set of pixels to quantify the radiative and nonradiative effects of afforestation. The space-for-time strategy makes our study performed at more local scale than Bright et al. (2017). Moreover, our use of the space-for-time strategy can help to compare the local surface temperature change between forest and open land calculated by the IBM method against the observed value at the continental scale. We also examined the relative benefit of one forest functional type over another in contributing to local surface temperature change. Investigation of the overall impact of afforestation over China is urgent since the Chinese government plans to expand afforestation in the near future (Bryan et al. 2018; Fu et al. 2017; Liu et al. 2008). We therefore seek to explore whether these plans are likely to warm or cool mainland China, and to help resolve the large uncertainty in the balance of radiative and nonradiative processes influencing local surface temperature over the midlatitudes.

\section{Methods and datasets}

\section{a. Space-for-time method}

A space-for-time strategy (Zhao and Jackson 2014) based on the land cover product was used to investigate the local impacts of afforestation. This method is based on the assumption that adjacent forest and open land pixels share the same background climate so that local differences between forest and open land pixels can be attributed to land cover change (Li et al. 2015; Peng et al. 2014; Zhao and Jackson 2014). Land cover type was derived from the Moderate Resolution Imaging Spectroradiometer (MODIS) yearly land cover product (MCD12C1, version 051; Friedl et al. 2010), which provides dominant land cover type based on the International Geosphere Biosphere Programme (IGBP) scheme (Table 1) at a spatial resolution of $0.05^{\circ}$ from 2001 to 2012. Year-to-year variation in land cover is common in the MODIS product, caused by either actual land cover changes or misclassification (Friedl et al. 2010). To minimize this problem, we only used pixels with the same class for at least 9 of the 12 years (from 2001 to 2012; Ma et al. 2017). A 12-yr synthesized land cover map is shown in Fig. 1a. In our study "forest" contains five IGBP classes including evergreen needleleaf $(\mathrm{ENF})$, evergreen broadleaf (EBF), deciduous needleleaf (DNF), deciduous broadleaf (DBF), and mixed (MF) forest. "Open land" contains grasslands 

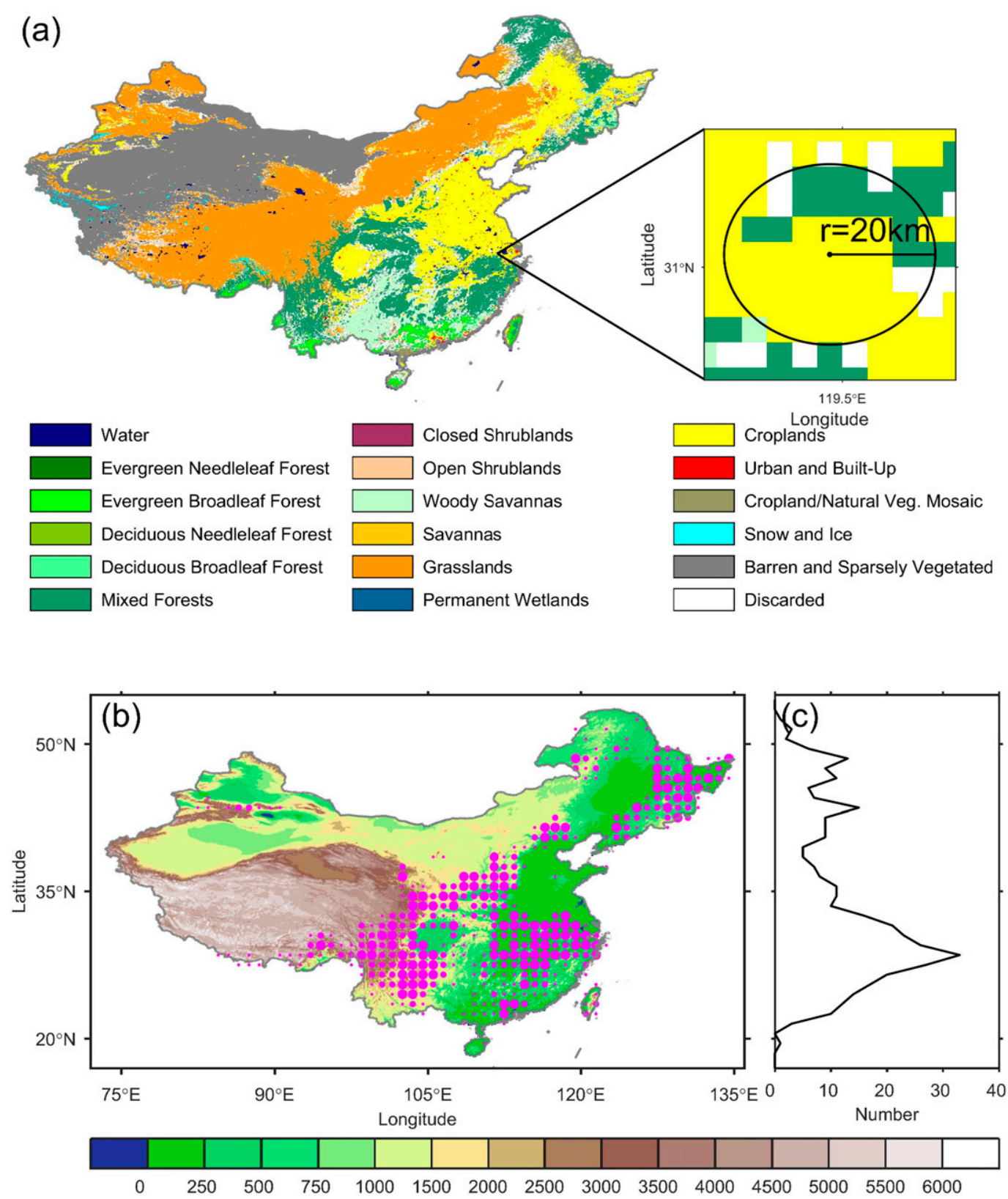

FIG. 1. (a) A 12-yr (2001-12) synthesized land cover map (see section 2) over mainland China and embedded schematic of the space-for-time method. To calculate the local differences between forest and open land in each paired site, in this example an average was first calculated over mixed forests and compared with the central croplands pixel (including both irrigated and rain-fed crops). This calculation was repeated for every croplands pixel. We than aggregated this to a $1^{\circ} \times 1^{\circ}$ grid cell. (b) Spatial and (c) latitudinal distribution of grid cells containing valid samples. Colors denote terrain height $(\mathrm{m})$. Large, medium, and small dots represent more than 40, between 10 and 40 , and less than 10 samples at each $1^{\circ} \times 1^{\circ}$ grid cell, respectively (note that calculations were performed at native resolution, but displayed at $1^{\circ} \times 1^{\circ}$ ).

(GRA) and croplands (CRO). Following the MODIS classification, CRO includes both rain-fed croplands (RFC) and irrigated croplands (IRC) (Table 1).

To pair adjacent forest and open land pixels, we defined a circle area with a radius of $20 \mathrm{~km}$ centered on an open land pixel (Fig. 1a). Any forest pixels within the circle area and the reference open land pixel were paired as a valid sample. To reduce the influence of altitudinal differences between the paired forest and open land pixels, especially on surface temperature, the forest 
TABLE 2. Details of the specific datasets used in this study.

\begin{tabular}{llccc}
\hline \hline \multicolumn{1}{c}{ Variables } & Resources & Time span & Temporal resolution & Spatial resolution \\
\hline Land cover & MCD12C1 & $2001-12$ & Yearly & $0.05^{\circ}$ \\
Land cover & MCD12Q1 & $2001-12$ & Yearly & $500 \mathrm{~m}$ \\
Irrigation area & HID & 2005 & Yearly & $5^{\prime}$ \\
Land surface temperature & MOD11C3 & $2001-12$ & Monthly & $0.05^{\circ}$ \\
& MYD11C3 & $2002-12$ & Monthly & $0.05^{\circ}$ \\
Albedo & GLASS & $2001-12$ & Monthly & $0.05^{\circ}$ \\
Albedo look-up maps & LUMs & - & Monthly & $0.05^{\circ}$ \\
Latent heat flux & MOD16A2 & $2001-12$ & - & $0.05^{\circ}$ \\
Elevation & SRTM30 & - & Monthly & $30^{\prime \prime}$ \\
Air temperature & ITPCAS & $2001-12$ & Monthly & $0.1^{\circ}$ \\
Precipitation & ITPCAS & $2001-12$ & Monthly & $0.1^{\circ}$ \\
Downward shortwave & ITPCAS & $2001-12$ & 8 days & $0.1^{\circ}$ \\
Downward longwave & ITPCAS & $2001-12$ & Monthly & $0.1^{\circ}$ \\
Leaf area index & GLASS & $2001-12$ & Monthly & $0.05^{\circ}$ \\
Snow cover & MOD10CM & $2001-12$ & & $0.05^{\circ}$ \\
& MYD10CM & $2002-12$ & & $0.05^{\circ}$ \\
\hline
\end{tabular}

pixels within the circle but with elevation bias exceeding $100 \mathrm{~m}$ compared with the reference open land pixel were discarded. Elevation was from the Shuttle Radar Topography Mission (SRTM30 version 2.0) digital elevation model with a spatial resolution of $30^{\prime \prime}$, and then aggregated to $0.05^{\circ}$ for consistent spatial resolution with land cover. The space-for-time strategy was applied to every open land pixel covering mainland China, producing 10971 samples in total. We then aggregated these samples to $1^{\circ} \times 1^{\circ}$ grid cells to aid visualization (Fig. 1b). Aggregating these samples to a finer resolution (e.g., $0.5^{\circ} \times 0.5^{\circ}$ ) causes negligible impact on our result (not shown). The $20-\mathrm{km}$ limit is within the range of distance limits specified in previous studies (Lee et al. 2011; Peng et al. 2014; Zhang et al. 2014; Zhao and Jackson 2014). A sensitivity test shows a very small impact from varying distance limits within reasonable range between adjacent forest and open land pixels ( $\mathrm{Li}$ et al. 2015).

\section{b. Quantification of the observed local impacts of afforestation}

Local impact of afforestation in each sample for a given year and month is quantified by

$$
\Delta \zeta=\overline{\zeta_{\text {forest }}}-\zeta_{\text {openland }}
$$

where $\zeta$ could denote a monthly climate variable [e.g., albedo $(\alpha)$, leaf area index (LAI), latent heat flux $\left(Q_{E}\right)$, sensible heat flux $\left(Q_{H}\right)$, and surface temperature $\left(T_{S}\right)$; Table 2]; the overbar represents the averaged value of the forest pixels in each sample. The monthly $\Delta \zeta$ was then averaged to achieve multiyear monthly mean or annual mean values of the $\zeta$ change.

Albedo $\alpha$ was obtained from the GLASS 8-day albedo product with a spatial resolution of $0.05^{\circ}$ (Liang and Liu
2012; Table 2). As the MODIS land cover product is only available from 2001 to 2012, we used the same time range for other data to ensure temporal consistency. The MODIS product provides directional hemispherical albedo (black-sky albedo), bihemispherical albedo (white-sky albedo), and actual albedo (blue-sky albedo), and we used the blue-sky albedo. We only used the "good" data (with the criterion of an uncertainty of less than 0.01 absolutely or $5 \%$ relatively) and "acceptable" data (with the criterion of an uncertainty of less than 0.05 absolutely or $10 \%$ relatively).

We used the GLASS 8-day LAI product from 2001 to 2012 derived from the MODIS surface reflectance products (Liang and Xiao 2012; Table 2) due to its relatively high spatial resolution $\left(0.05^{\circ}\right)$. Extensive validations demonstrate that the retrieval method used in the LAI product can estimate temporally continuous LAI profiles with better accuracy compared with current MODIS and CYCLOPES LAI products (Xiao et al. 2014). To match other data in the temporal resolution, both the GLASS 8-day $\alpha$ and LAI data were composed to monthly data (Gao et al. 2014).

We obtained $Q_{E}$ from the MODIS monthly terrestrial evapotranspiration product (MOD16A; Mu et al. 2011; Table 2) ranging from 2001 to 2012. The algorithm of MOD16A is based on the Penman-Monteith equation, which is implemented to calculate the soil evaporation, the canopy evaporation, and the plant transpiration. Following the separate calculations, all components are summed to achieve surface $Q_{E}(\mathrm{Mu}$ et al. 2011). The MOD16A terrestrial evapotranspiration product has been proven to perform well through validating estimated $Q_{E}$ against the observed values across 46 field-based eddy covariance flux towers (Running et al. 2017). 
Values of $T_{s}$ were obtained from MODIS Terra (MOD11C3, version 006) and Aqua (MYD11C3, version 006) monthly land surface temperature/emissivity products (Wan 2014) from 2001 to 2012 (MYD11C3 started from July 2002). Both provide daytime (1030 LT for Terra and 1330 LT for Aqua) and nighttime (2230 LT for Terra and $0130 \mathrm{LT}$ for $A q u a) T_{s}$ under clear-sky condition at a spatial resolution of $0.05^{\circ}$. Only "good quality data" and "other quality data" but with estimated emissivity error $\leq$ 0.02 and $T_{s}$ error $\leq 1 \mathrm{~K}$ were used ( $\mathrm{Li}$ et al. 2015). Daily mean $T_{s}$ can be estimated by averaging daytime and nighttime $T_{s}$ obtained either from MOD11C3 or MYD11C3. If the daily mean $T_{s}$ was available from both MOD11C3 and MYD11C3, we used the mean value of both; otherwise, we used the available one (Chen et al. 2017).

Because $Q_{H}$ cannot be directly acquired from satellite observations, the $Q_{H}$ change was calculated from the surface energy balance equation:

$$
\operatorname{SW} \downarrow(1-\alpha)+\mathrm{LW} \downarrow-\sigma T_{s}^{4}=Q_{H}+Q_{E}+G,
$$

where SW $\downarrow$ and LW $\downarrow$ are downward shortwave and longwave radiation, respectively, $\sigma$ is the StefanBoltzmann constant $\left(5.67 \times 10^{-8} \mathrm{~W} \mathrm{~m}^{-2} \mathrm{~K}^{-4}\right)$, and $G$ is the heat storage in the soil and biomass. As the space-fortime method assumes that the adjacent forest and open land pixels share the same background climate, the difference in $\mathrm{LW} \downarrow$ can be ignored. It is also reasonable to omit the difference in $G$ between adjacent forest and open land pixels as this value is negligible at time scales longer than one day (Lee et al. 2011). Ignoring the change in LW $\downarrow$ and $G$, the difference in $Q_{H}$ between forest and open land is

$$
\Delta Q_{H}=-\mathrm{SW} \downarrow \Delta \alpha-\sigma\left(T_{s, \text { forest }}^{4}-T_{s, \text { openland }}^{4}\right)-\Delta Q_{E},
$$

where $\Delta \alpha$ and $\Delta Q_{E}$ are the differences in albedo and latent heat flux, respectively, between forest and open land calculated from Eq. (1), and $T_{s, \text { forest }}$ and $T_{s \text {,openland }}$ are land surface temperature at forest and open land pixels, respectively; SW $\downarrow$ was from the China Meteorological Forcing Dataset (Yang et al. 2010) from 2001 to 2012 at a spatial resolution of $0.1^{\circ}$ (Table 2). The dataset is produced by merging multiple data sources and has the highest spatiotemporal resolution among all reanalysis data covering China. The $\mathrm{SW} \downarrow$ data were bilinearly interpolated to a spatial resolution of $0.05^{\circ}$. Note that as $\Delta Q_{H}$ is calculated based on other variables, $\Delta Q_{H}$ inevitably inherits uncertainties contained in other dataset including SW $\downarrow, \alpha$, and $Q_{E}$ and therefore a larger uncertainty in $\Delta Q_{H}$ should be expected.

\section{c. Attribution of local surface temperature change}

The IBM method (Lee et al. 2011) was used to attribute afforestation induced local $T_{s}$ change to radiative and nonradiative effects. The IBM method is derived based on some basic assumptions. In addition to the same amount of downward shortwave and longwave radiation received by adjacent forest and open land, the IBM method assumes air is sufficiently blended within the boundary so that air temperature at blending height is identical between forest and open land (Lee et al. 2011). This assumption is also supported by Winckler et al. (2018), who concluded that there is basically no difference in the temperatures of the lowest atmospheric layer between neighboring model grid boxes with forest and open land. Ignoring minor change in surface emissivity (Lee et al. 2011; Juang et al. 2007), changes in monthly mean $T_{s}$ due to land cover change can be decomposed into three terms:

$$
\Delta T_{s}=\frac{\lambda_{0}}{(1+f)} \Delta R_{n}^{*}+\frac{-\lambda_{0}}{(1+f)^{2}}\left(R_{n}^{*}-G\right) \Delta f+\frac{-\lambda_{0}}{(1+f)} \Delta G,
$$

where $\lambda_{0}$ is monthly mean land surface temperature sensitivity resulting from the longwave radiation feedback $\left(\lambda_{0}=1 / 4 \sigma T_{s}^{3}\right)$ and $f$ is the monthly mean energy redistribution factor:

$$
f=\frac{\rho C_{p}}{4 r_{a} \sigma T_{s}^{3}}\left(1+\frac{1}{\beta}\right),
$$

where $\rho$ is monthly mean air density, $C_{p}$ is monthly mean specific heat of air at constant pressure, $r_{a}$ is monthly mean aerodynamic resistance, $\beta$ is monthly mean Bowen ratio (defined as the ratio of monthly mean $Q_{H}$ and $Q_{E}$ ), and $R_{n}^{*}$ is monthly mean apparent net radiation:

$$
R_{n}^{*}=\mathrm{SW} \downarrow(1-\alpha)+\mathrm{LW} \downarrow-\sigma T_{a}^{4},
$$

where $T_{a}$ is monthly mean air temperature at a blending height within the atmospheric boundary layer, which approximates monthly surface air temperature. The IBM method further assumes $\Delta R_{n}^{*}=-\mathrm{SW} \downarrow \Delta \alpha$ and $R_{n}^{*} \approx$ $\mathrm{SW} \downarrow(1-\alpha)+\mathrm{LW} \downarrow-\sigma T_{s}^{4}$. The first, second, and third right-hand terms of Eq. (4) represent the afforestationinduced local $T_{s}$ change driven by $\alpha, f$, and $G$ change, respectively. Equation (4) slightly differs from the original IBM equation (Lee et al. 2011) as we retained the local $T_{s}$ change driven by $G$ to keep the consistency with the equation used by Bright et al. (2017). To differentiate, the local $T_{s}$ changes obtained from Eqs. (1) and (4) are called the observed and calculated $T_{s}$ change, respectively, hereafter. 


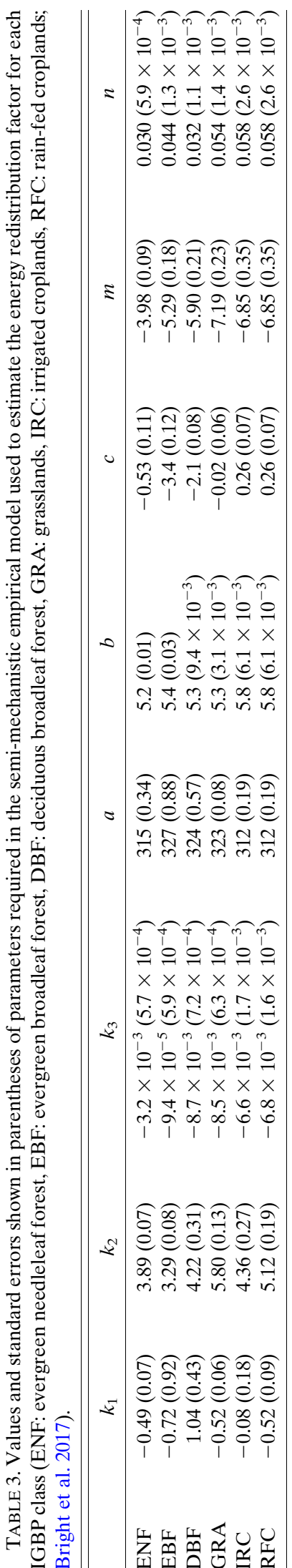

The aerodynamic resistance $r_{a}$, which is required in calculating $f$ [Eq. (5)], is absent at continental scale. Thus we estimated monthly mean vegetation dependent $f_{v}$ using a semi-mechanistic empirical $f$ model developed by Bright et al. (2017) as

$$
\begin{aligned}
f_{v}= & k_{1}+\frac{1 / 4 \sigma T_{a}}{k_{2} \exp \left(\alpha_{v}\right)+k_{3} P}\left[\mathrm{SW} \downarrow\left(1-\alpha_{v}\right)\right. \\
& \left.+\mathrm{LW} \downarrow-\mathrm{LW} \uparrow_{v}-G_{v}\right],
\end{aligned}
$$

where $k_{1}, k_{2}$, and $k_{3}$ are empirical parameters (Table 3 ) and $P$ is monthly total precipitation $\left(\mathrm{mm} \mathrm{month}^{-1}\right)$. The subscript $v$ used here denotes the vegetation dependent variable. Also, $\alpha_{v}, \mathrm{LW} \uparrow_{v}$, and $G_{v}$ were calculated following Bright et al. (2017) as

$$
\begin{aligned}
\alpha_{v} & =\alpha_{\mathrm{sc}, v}\left(F_{\mathrm{sc}}\right)+\alpha_{\mathrm{sf}, v}\left(1-F_{\mathrm{sc}}\right), \\
\mathrm{LW} \uparrow_{v} & =a+b\left(T_{a}\right)+c(\mathrm{LAI}), \quad \text { and } \\
G_{v} & =m+n \mathrm{SW} \downarrow_{v}\left(1-\alpha_{v}\right),
\end{aligned}
$$

where $\alpha_{\mathrm{sc}, v}$ and $\alpha_{\mathrm{sf}, v}$ are monthly mean albedo under snow cover and snow-free conditions respectively, $F_{\mathrm{sc}}$ is monthly mean snow cover percentage, LAI is multiyear (2001-12) annual mean leaf area index from GLASS, and $a, b, c, m$, and $n$ are empirical parameters derived from global FLUXNET data (Bright et al. 2017; Table 3).

The terms $\alpha_{\mathrm{sc}, v}$ and $\alpha_{\mathrm{sf}, v}$ were from multiscale climatological albedo look-up maps (LUMs; Gao et al. 2014), which provide monthly statistics of white-sky and blacksky albedo for each IGBP class for shortwave broadband under both snow-free and snow-covered conditions with a spatial resolution of $0.05^{\circ}$ (Table 2). It is generated using a multiscale hierarchical approach based on the MODIS bidirectional reflectance distribution function (BRDF)/albedo products from 2001 to 2011 and Landsat imagery. Unlike traditional look-up tables, the LUM data are geographically specific, which means that albedo for a given land cover type varies spatially to reflect the diversity in vegetation type, soil background or land management (Gao et al. 2014; Ghimire et al. 2014). To obtain the blue-sky albedo, we simply averaged the black-sky and white-sky albedo owing to a small difference and a high correlation coefficient between the average value and blue-sky albedo ( $\mathrm{Li}$ et al. 2015).

The term $F_{\text {sc }}$ was obtained by averaging snow cover percentages provided from MODIS Terra (MOD10CM, version 006) and Aqua (MYD10CM, version 006) monthly snow cover products (Hall and Riggs 2015) with a spatial resolution of $0.05^{\circ}$ from 2001 to 2012 (Table 2). 
The terms $T_{a}, P$, and $\mathrm{LW} \downarrow$ were from the China Meteorological Forcing Dataset (Yang et al. 2010) from 2001 to 2012 and bilinearly interpolated to a spatial resolution of $0.05^{\circ}$ (Table 2). All input variables in Eqs. (7)-(10) except LAI are multiyear averaged monthly mean values following Bright et al. (2017). Applying the IBM method and the $f$ model to each sample, we obtained the potential $T_{s}$ change as well as each component driven by $\alpha, f$, and $G$ change respectively caused by converting one forest class to one open land class.

\section{d. Calculation of actual $T_{s}$ change}

To facilitate comparing the calculated $T_{s}$ change against the observed value, we then calculated the actual $T_{s}$ change. The area percentage should be taken into consideration as one forest or open land pixel is often covered by multiple vegetation classes. We assume the calculated $T_{s}$ change caused by one conversion type is proportional to the area percentage of both classes before and after this conversion. Thus the actual $T_{s}$ change between forest and open land pixels in each sample is expressed as

$$
\Delta T_{s}=\sum_{i=\mathrm{GRA}, \mathrm{IRC}, \mathrm{RFC}} \sum_{j=\mathrm{ENF}, \mathrm{EBF}, \mathrm{DBF}} F_{i} F_{j} \Delta T_{s, i \rightarrow j},
$$

where $\Delta T_{s, i \rightarrow j}$ is potential $T_{s}$ change caused by land cover changing from class $i$ to $j$ calculated from Eqs. (4)-(10), $F_{i}$ is the area percentage of GRA, IRC, or $\mathrm{RFC}$ at the open land pixel, and $F_{j}$ is the averaged area percentage of ENF, EBF, or DBF at paired forest pixels for each sample.

The area percentage of each IGBP class at every pixel is provided in MCD12C1 but there are two challenges to overcome. First, a large portion of forest is dominated by mixed forest (MF) class in China (Fig. 1a), which cannot be calculated from Eqs. (7)-(10) due to missing parameters (e.g., $k_{1}, m$ ) required for this class. Second, the croplands are not separated into IRC and RFC in the MODIS land cover product. To compromise, we assume MF as a proportional combination of ENF, EBF, and DBF based on the area percentage of plant function type (PFT), which are multiyear averaged values in the same period from MCD12Q1 PFT scheme (Table 2, Fig. 2). The area percentage of IRC was from the Historical Irrigation Dataset (Siebert et al. 2015; see Table 2 and Fig. 2 herein). The residual of CRO by subtracting IRC is assumed as RFC (Fig. 2). DNF is not considered due to absent values of parameters (e.g., $\left.k_{1}, a, m\right)$ and its relative rarity in mainland China (Fig. 2). Similarly, the calculated $T_{s}$ change as well as local $T_{s}$ change driven by $\alpha, f$, and $G$ change from Eqs.
(4) to (11) were obtained at a spatial resolution of $0.05^{\circ}$ and then aggregated to $1^{\circ} \times 1^{\circ}$ grid cells to aid visualization and facilitate comparison between observed and calculated $T_{s}$ change.

\section{e. Quantification of the contribution from nonradiative effects}

The $T_{s}$ change driven by $\alpha\left[\Delta T_{s, \alpha} ;\right.$ first right-hand term of Eq. (4)] is defined as the radiative effect and both the $T_{s}$ change driven by $f\left[\Delta T_{s, f}\right.$; second righthand terms of Eq. (4)] and $G\left[\Delta T_{s, G}\right.$; third right-hand terms of Eq. (4)] are defined as the nonradiative effect. Thus, a non-radiative forcing index (NRFI; Bright et al. 2017) was used to compare the importance of the radiative and nonradiative effects of afforestation in driving local $T_{s}$ change:

$$
\mathrm{NRFI}=\frac{\left|\Delta T_{s, f}\right|+\left|\Delta T_{s, G}\right|}{\left|\Delta T_{s, \alpha}\right|+\left|\Delta T_{s, f}\right|+\left|\Delta T_{s, G}\right|} \times 100 \% .
$$

The NRFI ranges between $0 \%$ and $100 \%$, with a larger value corresponding to a stronger contribution from nonradiative effects of afforestation. The NRFI was also obtained at $0.05^{\circ}$ resolution and then aggregated to $1^{\circ} \times 1^{\circ}$ for better visualization.

\section{f. Significance test}

The statistical significance test used in our study is based on the two-tailed Student's $t$ test. We applied the $t$ test to each $1^{\circ} \times 1^{\circ}$ grid cell to examine whether the local biophysical difference between forest and open land pixels within each grid cell is statistically significant at a $95 \%$ confidence level.

\section{g. Uncertainty test}

The calculated $T_{s}$ change could be potentially affected by the reasonable ranges of the parameters (Table 3) employed in the $f$ model [Eq. (7)]. To quantify this impact, we performed an uncertainty test by adding a perturbation to the parameters in the $f$ model:

$$
\begin{aligned}
f_{v, \pm \sigma}= & \left(k_{1} \pm \sigma_{k_{1}}\right)+\frac{1 / 4 \sigma T_{a}}{\left(k_{2} \pm \sigma_{k_{2}}\right) \exp \left(\alpha_{v}\right)+\left(k_{3} \pm \sigma_{k_{3}}\right) P} \\
& \times\left[\mathrm{SW} \downarrow\left(1-\alpha_{v}\right)+\mathrm{LW} \downarrow-\mathrm{LW} \uparrow_{v}-G_{v}\right],
\end{aligned}
$$

where the terms $\sigma_{k_{1}}, \sigma_{k_{2}}$, and $\sigma_{k_{3}}$ are the standard errors of $k_{1}, k_{2}$, and $k_{3}$ respectively (Table 3 ). Equation (13) 

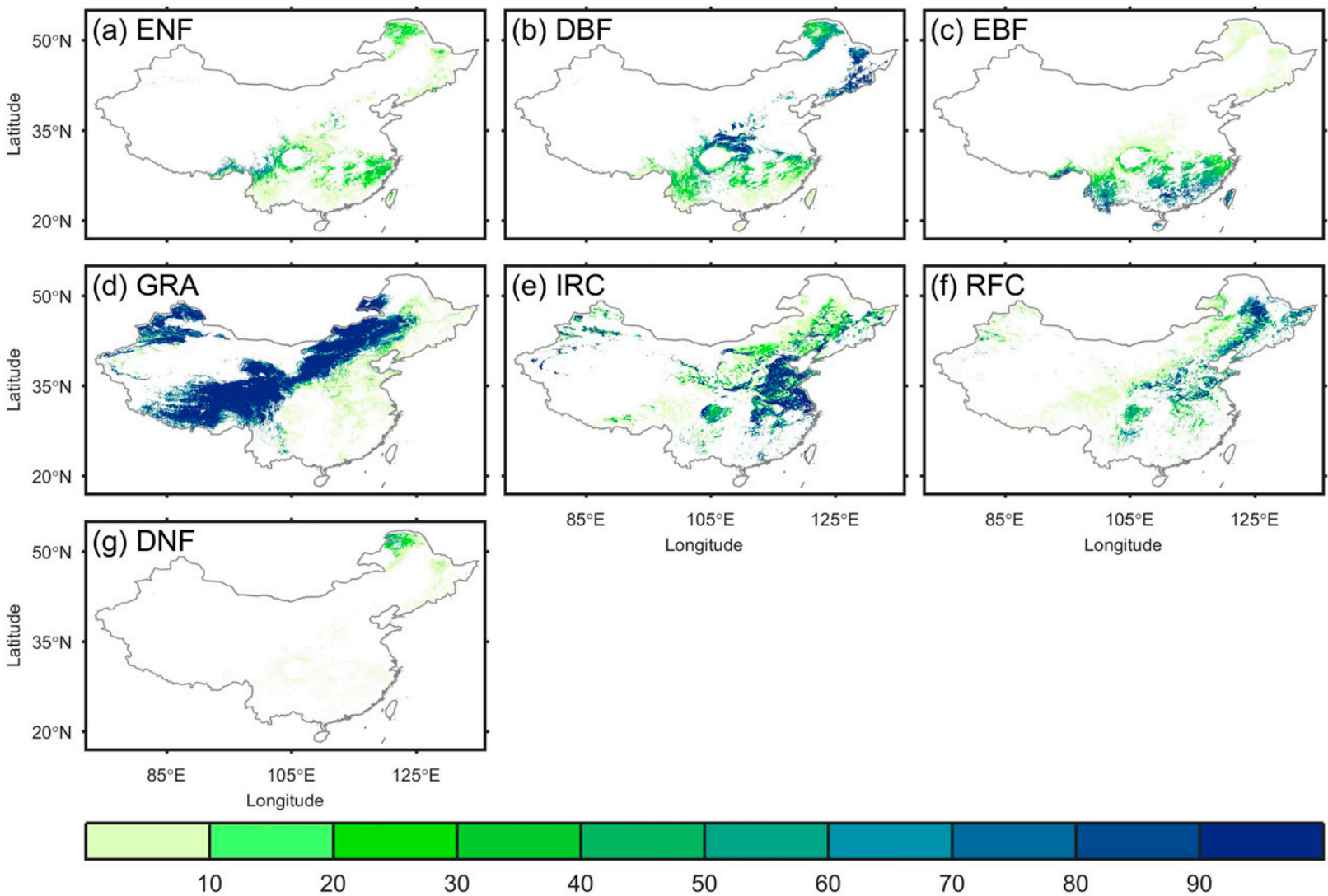

60

70

80

90

FIG. 2. Area percentage (\%) of (a) evergreen needleleaf forest, (b) deciduous broadleaf forest, (c) evergreen broadleaf forest, (d) grasslands, (e) irrigated croplands, (f) rain-fed croplands, and (g) deciduous needleleaf forest at a spatial resolution of $0.05^{\circ}$ over mainland China.

shows that $f_{v}$ is calculated with plus and minus one standard error in the parameters $k_{1}, k_{2}$, and $k_{3}$, respectively. Other parameters $(a, b, c, m$, and $n)$ are not considered here owing to more negligible influences caused by the reasonable variations in these parameters (Bright et al. 2017). We note that we are not trying to quantify the range of the calculated $T_{s}$ change induced by the uncertainty in the parameters owing to a highly nonlinear relationship between the calculated $T_{s}$ change and those parameters. Instead we simply test how much the calculated $T_{s}$ change can be impacted by plus or minus a standard error in the parameters utilized in the $f$ model.

\section{Results}

\section{a. Impacts on land surface biophysical parameters}

Converting open land to forest directly affects the land surface biophysical parameters (e.g., $\alpha, \mathrm{LAI}$, and $Z_{0}$ ) and we therefore first examined differences between forest and open land. Averaged over the colored grid cells, forest has a lower $\alpha(-2.63 \% \pm 2.72 \%$, spatial mean \pm spatial standard deviation hereafter) than open land (Fig. 3a). The $\alpha$ difference between forest and open land varies spatially, with a larger decrease $(>15 \%)$ in the high latitudes and altitudes, and a smaller decrease $(<3 \%)$ in most mid- and low latitudes and altitudes (Figs. 1b, 3a). This spatial heterogeneity of $\alpha$ change is associated with snow cover that is common or long-lived at high latitudes and high altitudes. Snow cover is infrequent or short lived in middle and low latitudes and altitudes [see Li et al. (2008) for details of the temporal and spatial variability in show cover over China]. Under snow cover conditions $\alpha$ can be further decreased by the "masking effect" of snow under taller canopy of forest. This is more evident from an enhanced $\alpha$ decrease shown at high latitudes in cold seasons (Fig. 3b). Forest has a greater LAI $\left(0.70 \pm 0.37 \mathrm{~m}^{2} \mathrm{~m}^{-2}\right)$ than open land averaged over the colored grid cells (Fig. 3c). A larger increase in LAI occurs in the southeast coastal region (Fig. 3c) mainly due to a large proportion of EBF 

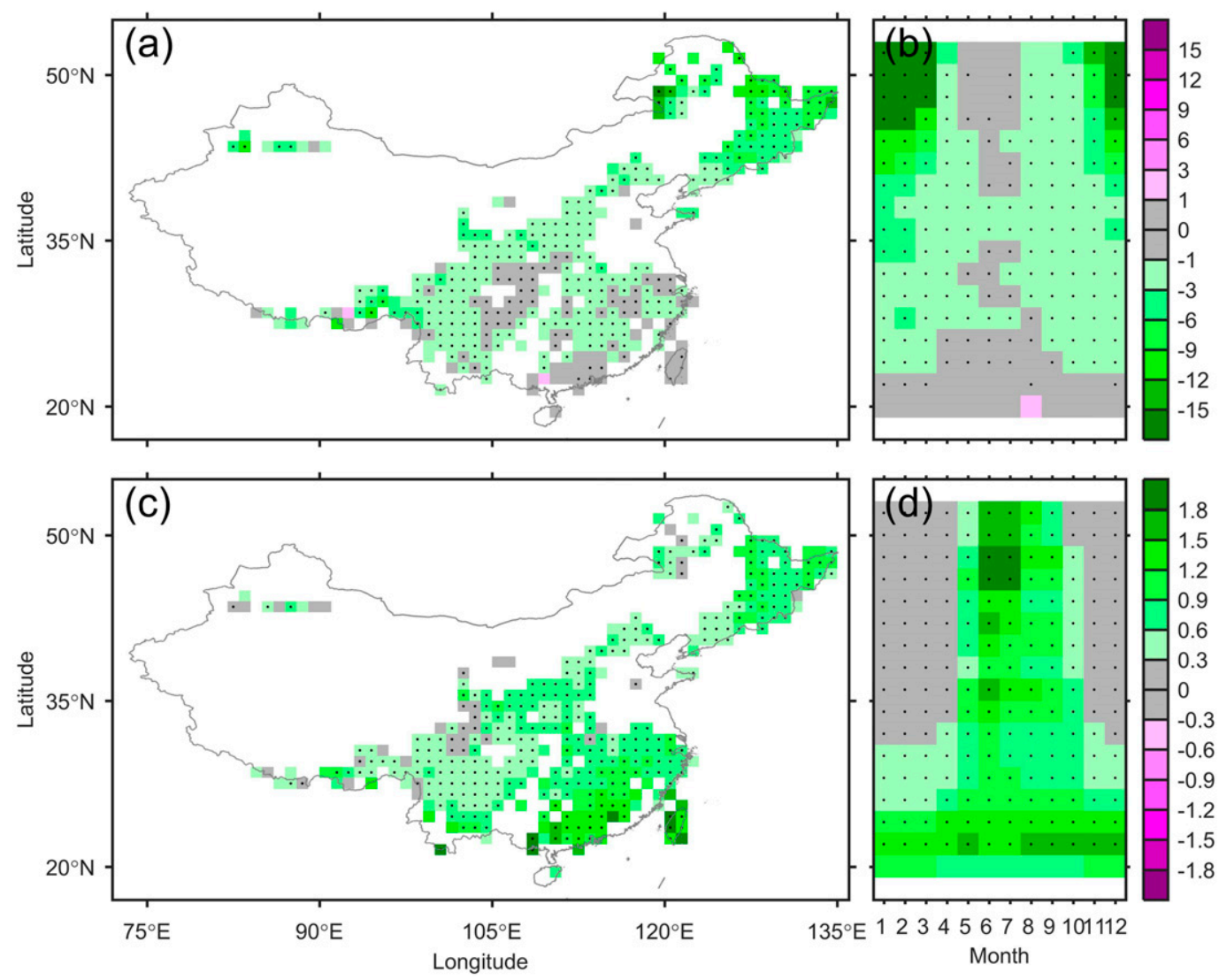

FIG. 3. Annual mean differences in (a) albedo $\alpha\left(\%\right.$,) and (c) LAI $\left(\mathrm{m}^{3} \mathrm{~m}^{-3}\right)$ between forest and open land (forest minus open land), and seasonal and latitudinal differences in (b) $\alpha$ and (d) LAI between forest and open land (forest minus open land). Black dots denote significance at the $95 \%$ level tested by a two-tailed Student's $t$ test.

(Fig. 2c), which can maintain a larger LAI than open land throughout the year (Fig. 3d). For other regions dominated by DBF, LAI increases more in warm seasons $\left(>0.6 \mathrm{~m}^{2} \mathrm{~m}^{-2}\right)$ and changes little in cold seasons $\left(<0.3 \mathrm{~m}^{2} \mathrm{~m}^{-2}\right)$ (Fig. 3d). As would be expected, replacing open land with forest darkens and "greens" the surface. Overall, the magnitude of changes in $\alpha$ and LAI mainly depends on seasonal snow cover and the type of forest grown respectively.

Forests usually have a greater $Z_{0}$ than open land owing to their height and canopy structure (Monteith 1975 ). While an increase in LAI would tend to increase $Q_{E}$ if moisture is available, a greater $Z_{0}$ increases both $Q_{H}$ and $Q_{E}$ at the same time through enhanced turbulence. How the surface available energy is partitioned between $Q_{H}$ and $Q_{E}$ changes due to afforestation thus depends on how both LAI and $Z_{0}$ change. The energy redistribution factor $f$ derived from the IBM method is inversely related to both aerodynamic resistance and the Bowen ratio [Eq. (5)], suggesting $f$ can be intensified by high surface roughness and larger evapotranspiration.
The $f$ is therefore a measure of the combined biophysical and physiological control of vegetation on energy partitioning. Converting open land to forest causes an increase in $f$ in most cases, but the magnitude of the change varies with forest and open land types (Fig. 4). A larger increase in $f$ can be achieved by converting open land to EBF, while a smaller increase in $f$ occurs when open land is replaced by DBF. The choice of open land types can further modulate this process and converting GRA and RFC to forest tends to cause a larger $f$ increase, but converting IRC to forest leads to a smaller increases in $f$. These discrepancies in $f$ responses to various conversion types are mainly explained by a large difference in $f$ change in warm seasons, when converting GRA or RFC to EBF increases $f$ by up to 4.0 but converting IRC to DBF increases $f$ by no more than 1.0 and decreases $f$ occasionally (Fig. 5).

\section{b. Impacts on land surface fluxes}

We next examined how the land surface fluxes respond to biophysical change. Averaging over the colored grid 

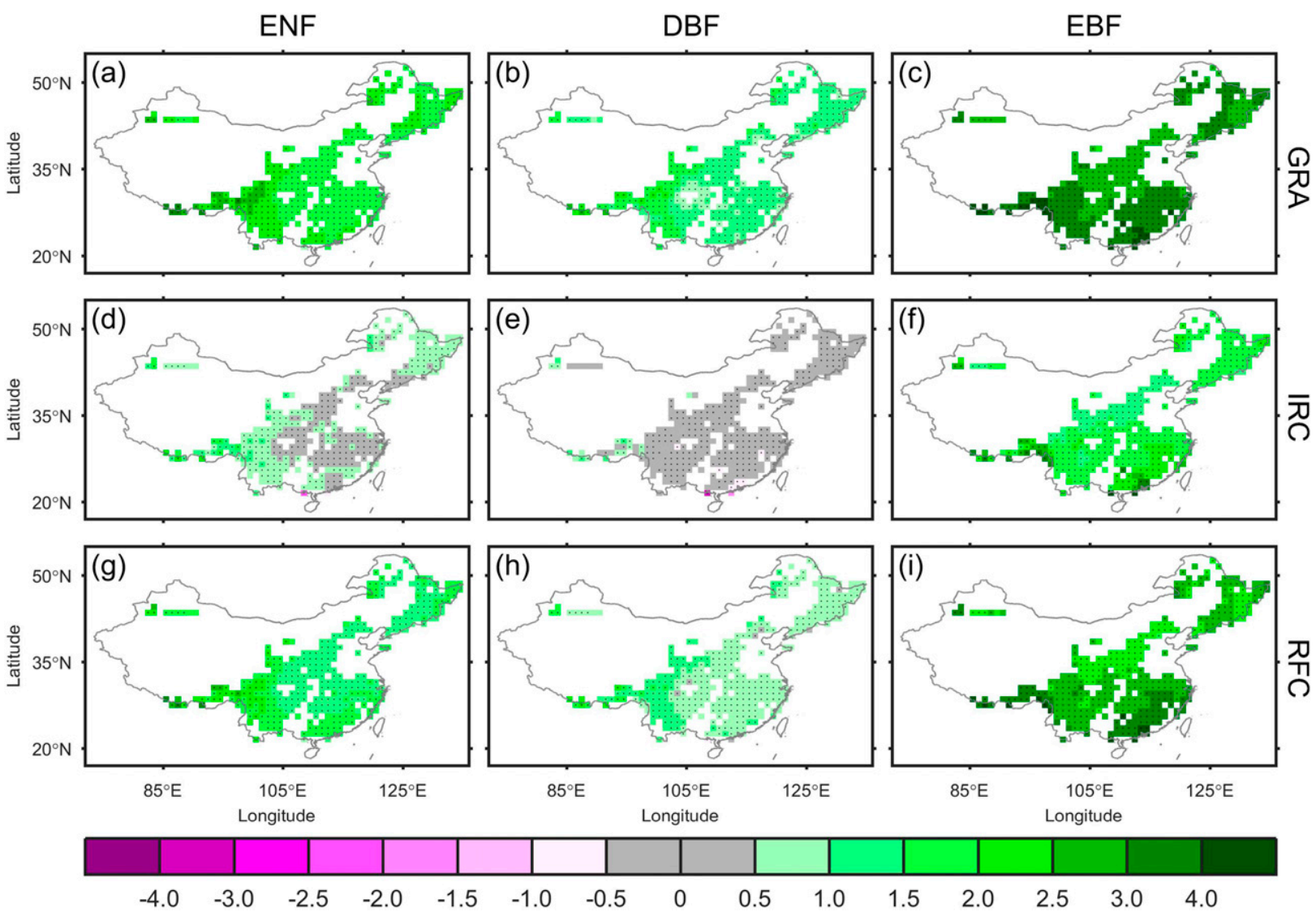

FIG. 4. Annual mean differences in energy redistribution factor $f$ between forest (ENF: evergreen needleleaf forest, DBF: deciduous broadleaf forest, EBF: evergreen broadleaf forest) and open land (GRA: grasslands, IRC: irrigated croplands, RFC: rain-fed croplands, forest minus open land). Changes with respect to (left) ENF, (center) DBF, and (right) EBF. Changes with respect to (a)-(c) GRA, (d)(f) IRC, and (g)-(i) RFC. For example, (a) shows the difference in $f$ between ENF and GRA. Black dots denote significance at the $95 \%$ level tested by a two-tailed Student's $t$ test.

cells, forest has a larger $Q_{E}\left(4.91 \pm 5.20 \mathrm{~W} \mathrm{~m}^{-2}\right)$ than open land at annual scales (Fig. 6a). Locally, the increase in $Q_{E}$ can exceed $25 \mathrm{~W} \mathrm{~m}^{-2}$, such as in the southeast coast region; however, the $Q_{E}$ change is negligibly small in a few western regions. The $Q_{H}$ difference between forest and open land is overall small $\left(0.49 \pm 7.00 \mathrm{~W} \mathrm{~m}^{-2}\right)$ over colored grid cells because of a large spatial variability, varying from an increase of exceeding $25 \mathrm{~W} \mathrm{~m}^{-2}$ in the west to a decrease of up to $20 \mathrm{~W} \mathrm{~m}^{-2}$ in the southeast (Fig. 6c). The $Q_{H}$ change presents clear seasonal variations, with an increase in cold seasons and a decrease in warm seasons (Fig. 6d). The term $Q_{E}$ shows an opposite overall pattern to $Q_{H}$ although the change in cold seasons is very weak (Fig. 6b). These latitudinal and seasonal variations of $Q_{H}$ and $Q_{E}$ are closely associated with the biophysical changes. Specifically, afforestation increases LAI (Figs. 3c,d) and $Z_{0}$, which increase the evapotranspiration efficiency (represented by $f$; Figs. 4 and 5). Also, $Q_{E}$ is further enhanced by the decrease in $\alpha$ (Figs. 3a,b). In addition, we also note an important role of background climate in determining $Q_{H}$ and $Q_{E}$ changes driven by afforestation. This is evident in some western and northern regions that are characterized by arid or semiarid background climate (Fig. 6a). Here, the impact of afforestation on $Q_{E}$ is likely to be water limited. In this case the increased absorbed radiation caused by the $\alpha$ decrease is more efficiently dissipated via $Q_{H}$ over forest (Fig. 6c) enabled by the larger $Z_{0}$ and lower aerodynamic resistance. This phenomenon was also previously reported in other semiarid regions where forest is compared to open land (Rotenberg and Yakir 2010).

\section{c. Impacts on land surface temperature}

The observed $T_{s}$ change between forest and open land over the colored grid cells mainly shows a cooling effect $\left(-0.32^{\circ} \pm 0.37^{\circ} \mathrm{C}\right)$ at the annual scale (Figs. $7 \mathrm{a}$ and 8$)$. Coincident with the biophysical and surface fluxes changes, the observed $T_{s}$ change depicts seasonal and latitudinal variability, with a cooling in warm seasons and warming in cold seasons at high latitudes (Fig. 7b). 

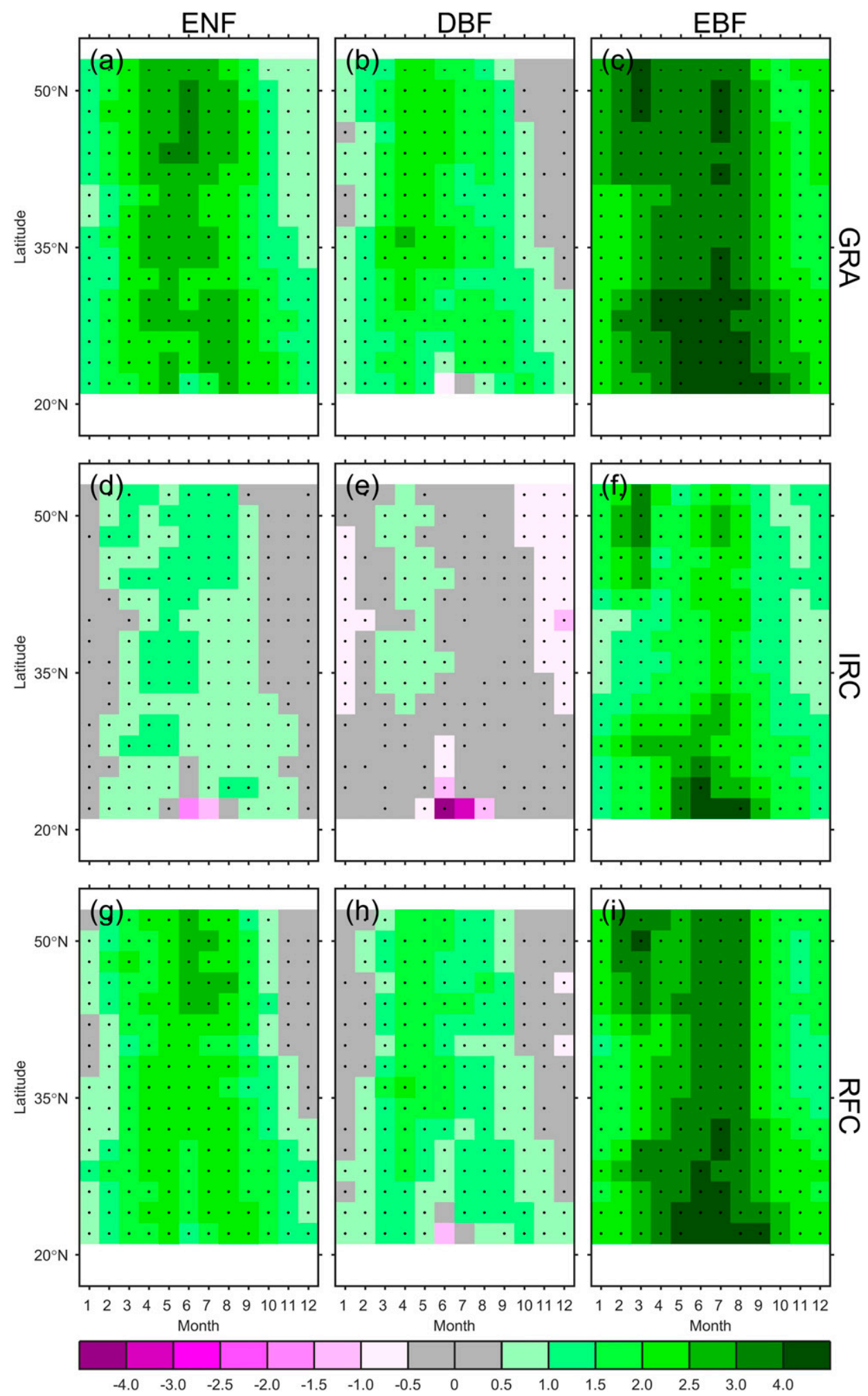

FIG. 5. Seasonal and latitudinal differences in energy redistribution factor $f$ between forest (ENF, DBF, EBF) and open land (GRA, IRC, RFC, forest minus open land). Changes with respect to (left) ENF, (center) DBF, and (right) EBF. Changes with respect to (a)-(c) GRA, (d)-(f) IRC, and (g)-(i) RFC. For example, (a) shows the difference in $f$ between ENF and GRA. Black dots denote significance at the $95 \%$ level tested by a two-tailed Student's $t$ test. 

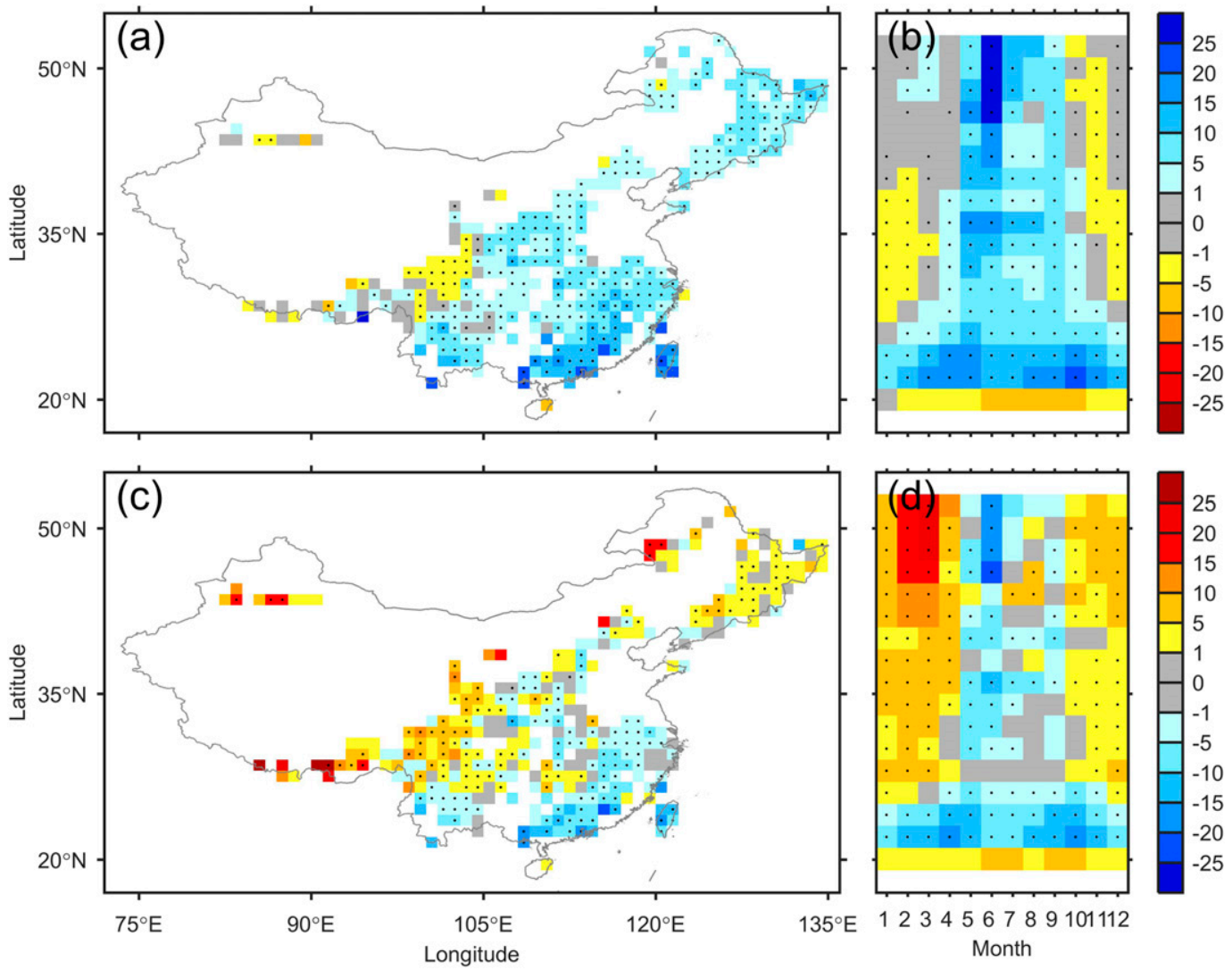

FIG. 6. Annual mean differences in (a) latent heat flux $Q_{E}\left(\mathrm{~W} \mathrm{~m}^{-2}\right)$ and (c) sensible heat flux $Q_{H}\left(\mathrm{~W} \mathrm{~m}^{-2}\right)$ between forest and open land (forest minus open land), and seasonal and latitudinal differences in (b) $Q_{E}$ and (d) $Q_{H}$ between forest and open land (forest minus open land). Black dots denote significance at the $95 \%$ level tested by a two-tailed Student's $t$ test.

Before the attribution of afforestation induced local $T_{s}$ change to radiative and nonradiative effects, we first validated the calculated $T_{s}$ change against the observed value. Annually the calculated $T_{s}$ change can produce a similar cooling effect $\left(-0.53^{\circ} \pm 0.48^{\circ} \mathrm{C}\right)$ compared to the observed $T_{s}$ change over the colored grid cells (Figs. 7c and 8). A larger difference between the observed and calculated $T_{s}$ changes mainly occurs in the southwestern and northeastern regions (Figs. 7a,c). In terms of latitudinal and seasonal pattern, the calculated and observed $T_{s}$ changes are overall consistent, with the calculated $T_{s}$ change showing a warm bias at high latitudes in cold seasons and a cooling bias at low latitudes in warm seasons (Figs. 7b,d). In general, the calculated $T_{s}$ change is spatially and temporally consistent with the observed $T_{s}$ change (Figs. 7a-d) although with some discrepancies between them, which are detailed in the discussion section (section 4). The calculated $T_{s}$ change caused by afforestation is a function of forest and open land classes (Figs. 9-11). In each conversion type, the area percentages of forest and open land classes are not considered, indicating a theoretical maximum potential local $T_{s}$ change associated with afforestation. A larger decrease in local $T_{s}$ can be achieved by converting open land to EBF, followed by ENF and DBF (Figs. 9 and 10). Among all conversion types, replacing GRA with EBF has the largest cooling effect on local $T_{s}\left(-4.35^{\circ} \pm 1.15^{\circ} \mathrm{C}\right)$, although replacing GRA with ENF and DBF also results in about half the amount of cooling. Converting RFC to forests has a similar cooling effect to the GRA cases. However, the choice of IRC can weaken the cooling effect of afforestation, and occasionally generates an unexpected warming effect. This large variability in the cooling effect associated with different conversion types is mainly attributed to the local $T_{s}$ change in warm seasons or at low latitudes (Fig. 11). In these cases local $T_{s}$ can be decreased by over $5^{\circ} \mathrm{C}$ when GRA is converted to EBF but the replacement of IRC by DBF causes negligible change in local $T_{s}$. In cold seasons and at high latitudes afforestation always causes a warming effect. 

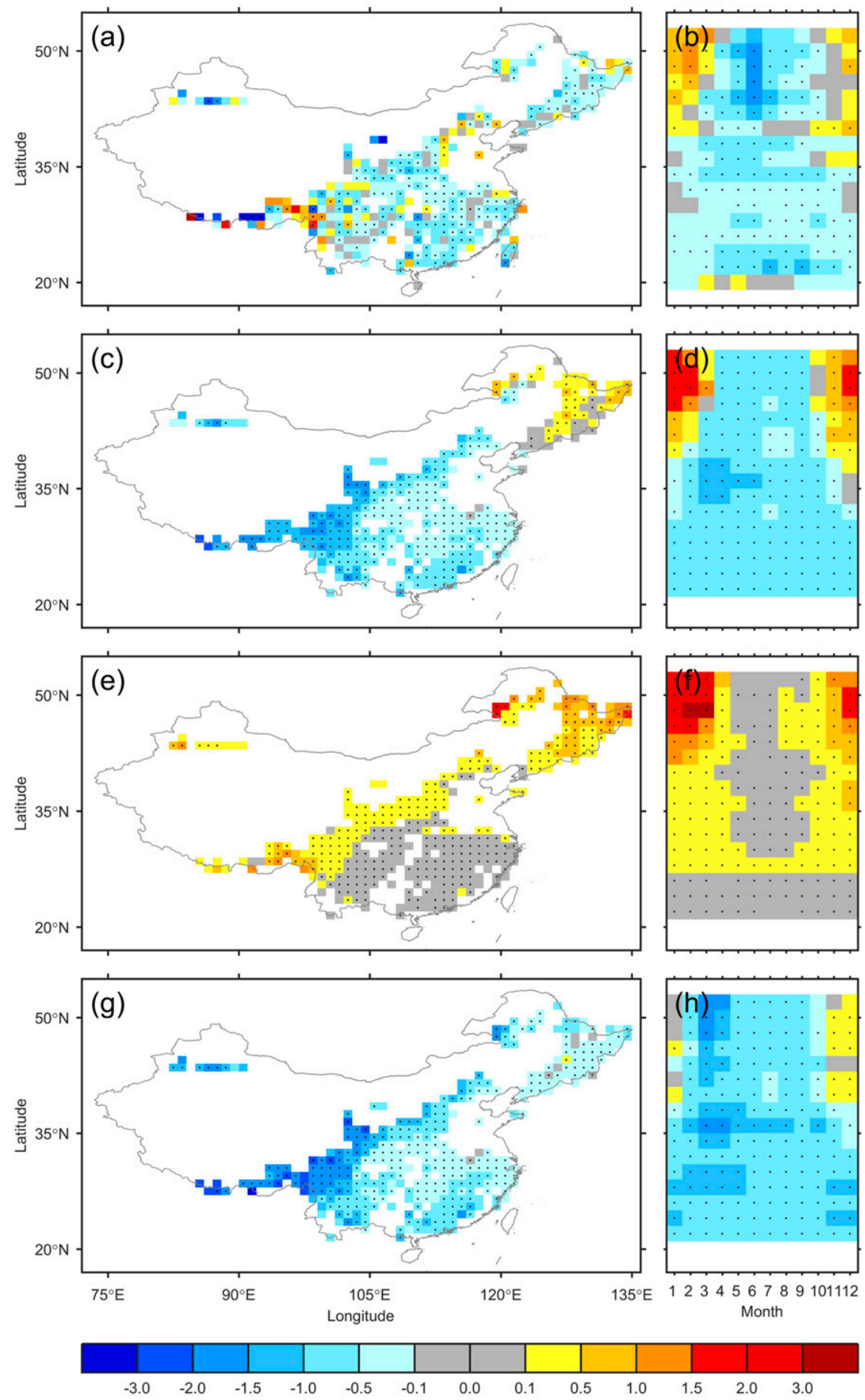

FIG. 7. Annual mean values of (a) the observed surface temperature change $\Delta T_{s, \text { obs }}\left({ }^{\circ} \mathrm{C}\right)$, (c) the calculated $T_{s}$ change $\Delta T_{s \text {,cal }}\left({ }^{\circ} \mathrm{C}\right)$, (e) the $T_{s}$ change driven by albedo change $\Delta T_{s, \alpha}\left({ }^{\circ} \mathrm{C}\right)$, and $(\mathrm{g})$ the $T_{s}$ change driven by energy redistribution factor change $\Delta T_{s, f}\left({ }^{\circ} \mathrm{C}\right)$ between forest and open land (forest minus open land), and seasonal and latitudinal (b) $\Delta T_{s, \text { obs }}$, (d) $\Delta T_{s, \text { cal }}$, (f) $\Delta T_{s, \alpha}$, and (h) $\Delta T_{s, f}$ between forest and open land (forest minus open land). Black dots denote significance at the $95 \%$ level tested by a two-tailed Student's $t$ test. 


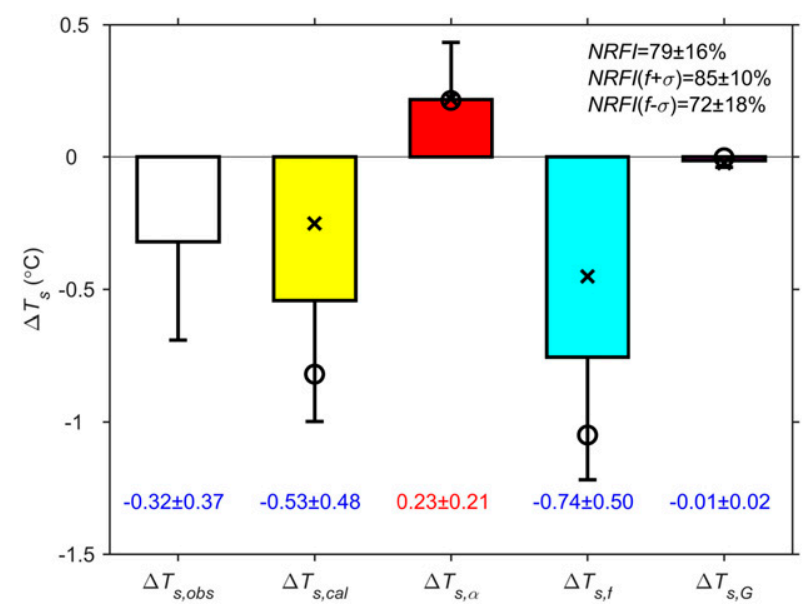

FIG. 8. Annual mean values of the observed surface temperature change $\Delta T_{s, \text { obs }}\left({ }^{\circ} \mathrm{C}\right)$, the calculated surface temperature change $\Delta T_{s \text {, cal }}\left({ }^{\circ} \mathrm{C}\right)$, the surface temperature change driven by albedo change $\Delta T_{s, \alpha}\left({ }^{\circ} \mathrm{C}\right)$, the surface temperature change driven by energy redistribution factor change $\Delta T_{s, f}\left({ }^{\circ} \mathrm{C}\right)$, and the surface temperature change driven by the heat storage change $\Delta T_{s, G}\left({ }^{\circ} \mathrm{C}\right)$ between forest and open land (forest minus open land) averaged over colored grid cells (Fig. 7). The vertical error bar denotes the standard deviation. The circle and cross represent the values achieved by plus $(f+\sigma)$ or minus $(f-\sigma)$ a standard error in the parameters utilized in the $f$ mode (see section 2$)$, respectively. The values (spatial mean \pm spatial standard deviation) of surface temperature change are provided at the bottom, and the nonradiative forcing index (NRFI) is provided at the top-right corner.

The radiative process driven by the $\alpha$ change causes a warming effect of $0.23^{\circ} \mathrm{C}\left( \pm 0.21^{\circ} \mathrm{C}\right)$ on annual mean local $T_{s}$ over the colored grid cells (Figs. 7e and 8). Larger values $\left(>0.5^{\circ} \mathrm{C}\right)$ mainly occur in the boreal and some mountain regions (Fig. 7f) due to an amplified $\alpha$ increase in cold seasons associated with snow (Fig. 3a). Forest and open land classes have a negligible impact on the radiative effect at annual scales, with a slightly larger warming effect achieved when open land is converted to ENF (Figs. 10 and 12). This can be mostly explained by a larger increase in local $T_{s}$ driven by the change in $\alpha$ in warm seasons when open land is converted to ENF (up to $1.0^{\circ} \mathrm{C}$; Fig. 13 ).

The nonradiative process associated with $f$ change generates a cooling effect of $-0.74^{\circ} \mathrm{C}\left( \pm 0.50^{\circ} \mathrm{C}\right)$ on the annual mean local $T_{s}$ over all colored grid cells (Figs. $7 \mathrm{~g}$ and 8). A much stronger cooling effect occurs in southwestern region, explaining much of the cooling bias in the calculated $T_{s}$ change compared with the observed value. In contrast with the radiative effect, the cooling effect driven by $f$ change is relatively small in cold seasons but prominent in warm seasons (Fig. 7h). The $f$ change-induced local $T_{s}$ change is also strongly dependent on forest and open land class (Figs. 10, 14, and 15). On annual time scales, a much stronger cooling effect can be achieved by planting EBF, followed by ENF and DBF (Figs. 10 and 14). In terms of open land types, a similar amount of cooling generated by $f$ change can be maintained in GRA- and RFC-related conversions, while it is diminished in IRC-related conversion. On seasonal scale, the cooling effect varies from over $-5^{\circ} \mathrm{C}$ for GRA or RFC cases to negligibly small when IRC is converted to DBF in warm seasons. We also note that a large discrepancy in the local $T_{s}$ change driven by $f$ change occurs at high latitudes in cold seasons. Here, converting IRC to DBF mostly causes warming (up to $2^{\circ} \mathrm{C}$ ) while converting RFC to EBF mostly cools $\left(\right.$ by $\left.5^{\circ} \mathrm{C}\right)$. The contribution of soil and biomass heat storage to local $T_{s}$ change perturbed by afforestation is negligible across all latitudes, seasons, and conversion types (not shown).

To compare the radiative and nonradiative effects, a nonradiative forcing index (NRFI) (see section 2) was utilized. Overall annual mean NRFI averaged over the colored grids is $79 \%( \pm 16 \%)$, indicating that the nonradiative effect is much more important than the radiative effect (Fig. 8). Consistent with radiative and nonradiative effects, annual mean NRFI increases as latitude decreases, and its magnitude varies with forest and open land types (Fig. 16). In most cases NRFI remains above $50 \%$ except for some regions north of $45^{\circ} \mathrm{N}$ when IRC is converted to ENF and DBF or RFC is converted to DBF. Averaging over all colored grid cells, the larger NRFI (ranging from $85 \%$ to $90 \%$ ) occurs in the EBF-related conversions due to a larger cooling effect driven by $f$ change (Fig. 10). The smallest NRFI of $53 \%$ occurs when IRC is converted to ENF.

\section{d. Sensitivity of the calculated $T_{s}$ change to the parameters}

The calculated $T_{s}$ change caused by afforestation based on the IBM method can be impacted by the reasonable variations in the parameters employed in the $f$ model (Fig. 8). The calculated $T_{s}$ change varies from $-0.82^{\circ}$ to $-0.25^{\circ} \mathrm{C}$ with plus and minus a standard error in the parameters, respectively. Not surprisingly, such a variation of the calculated $T_{s}$ change mostly results from a strong sensitivity of $f$ change-induced local $T_{s}$ change to the parameters. However, $\alpha$ and $G$ changeinduced local $T_{s}$ changes show very weak sensitivity to the uncertainty in the parameters. Accordingly NRFI varies from $85 \%$ to $72 \%$ with plus and minus a standard error in the parameters respectively (Fig. 8).

The sensitivity of the calculated $T_{s}$ change to the uncertainty in the parameters also depends on the conversion types. This impact is evident in the DBF-related conversion types but is very small in other conversion types (Fig. 10). For example, the calculated $T_{s}$ changes 

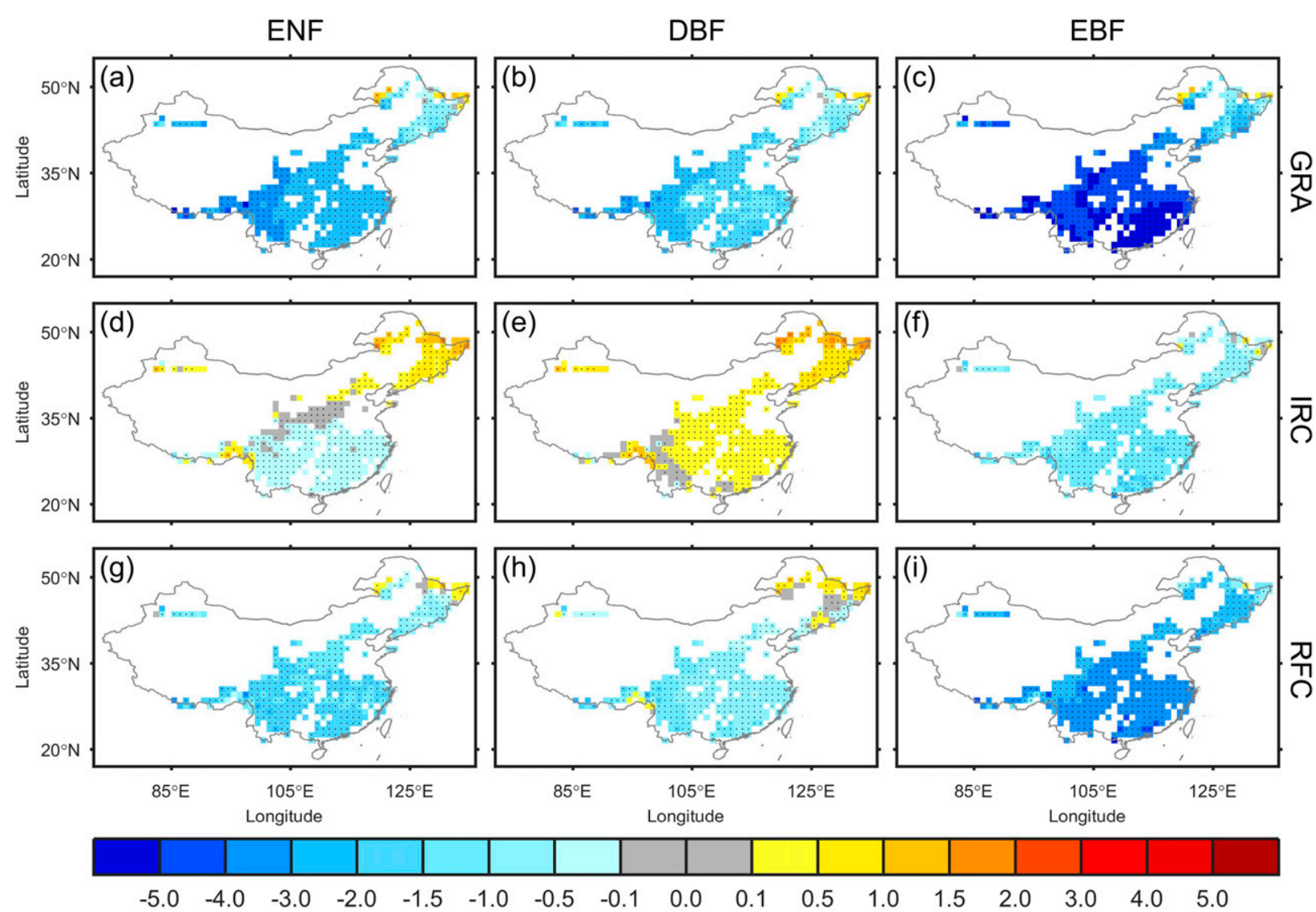

FIG. 9. Annual mean values of the calculated surface temperature change $\Delta T_{s, \text { cal }}\left({ }^{\circ} \mathrm{C}\right)$ between forest $(\mathrm{ENF}, \mathrm{DBF}$, EBF) and open land (GRA, IRC, RFC, forest minus open land). Changes with respect to (left) ENF, (center) DBF, and (right) EBF.Changes with respect to (a)-(c) GRA, (d)-(f) IRC, and (g)-(i) RFC. For example, (a) shows $\Delta T_{s \text {,cal }}$ between ENF and GRA. Black dots denote significance at the $95 \%$ level tested by a two-tailed Student's $t$ test.

are $-2.05^{\circ}$ and $0.75^{\circ} \mathrm{C}$, and NRFI values are $88 \%$ and $64 \%$, as a result of plus and minus a standard error in the parameters, respectively, when RFC is converted to DBF (Fig. 10h).

This highlights a large uncertainty in the calculated $T_{s}$ change and NRFI caused by the parameters used in the $f$ model, especially in the case of replacing open land with DBF. We also note that NRFI always stays above $50 \%$ in most cases despite the uncertainty in parameters. It suggests that the dominant role of nonradiative effect of afforestation in driving local $T_{s}$ is robust although uncertainty remains in the calculated $T_{s}$ change.

\section{Discussion}

Using satellite observations, we investigated the local biophysical difference between forest and open land over mainland China. We also attributed local surface temperature change between forest and open land to radiative and nonradiative effects. Based on the satellite observations and the space-for-time method, the annual mean local $T_{s}$ change between adjacent forest and open land is observed to be $-0.32^{\circ} \mathrm{C}\left( \pm 0.37^{\circ} \mathrm{C}\right)$, which is broadly consistent with previous studies (Ma et al. 2017; Peng et al. 2014). Although these studies also used the space-for-time method based on satellite observation, they did not attribute the local $T_{s}$ changes between adjacent forest and open land to radiative and nonradiative processes. We therefore quantified the radiative and nonradiative effects in driving the local $T_{s}$ change between forest and open land at a continental scale over China based on the IBM method (Lee et al. 2011) combined with the $f$ model (Bright et al. 2017). In our analysis, the radiative process associated with the $\alpha$ change leads to a local warming of $0.23^{\circ} \mathrm{C}\left( \pm 0.21^{\circ} \mathrm{C}\right)$ and the nonradiative process associated with energy partitioning leads to a local cooling of $-0.74^{\circ} \mathrm{C}\left( \pm 0.50^{\circ} \mathrm{C}\right)$ and resulting a local cooling of $-0.53^{\circ} \mathrm{C}\left( \pm 0.48^{\circ} \mathrm{C}\right)$ in total when converting open land to adjacent forest. Importantly, the nonradiative effect explains about $79 \%$ of 
ENF
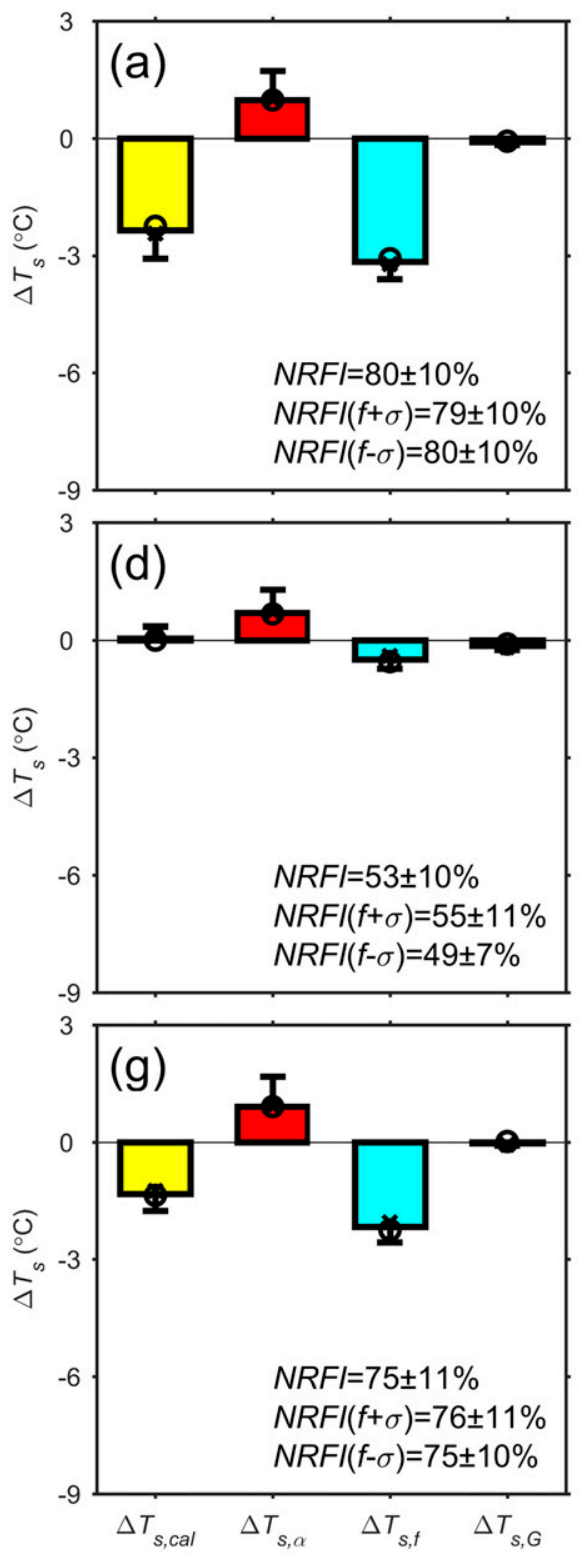

DBF
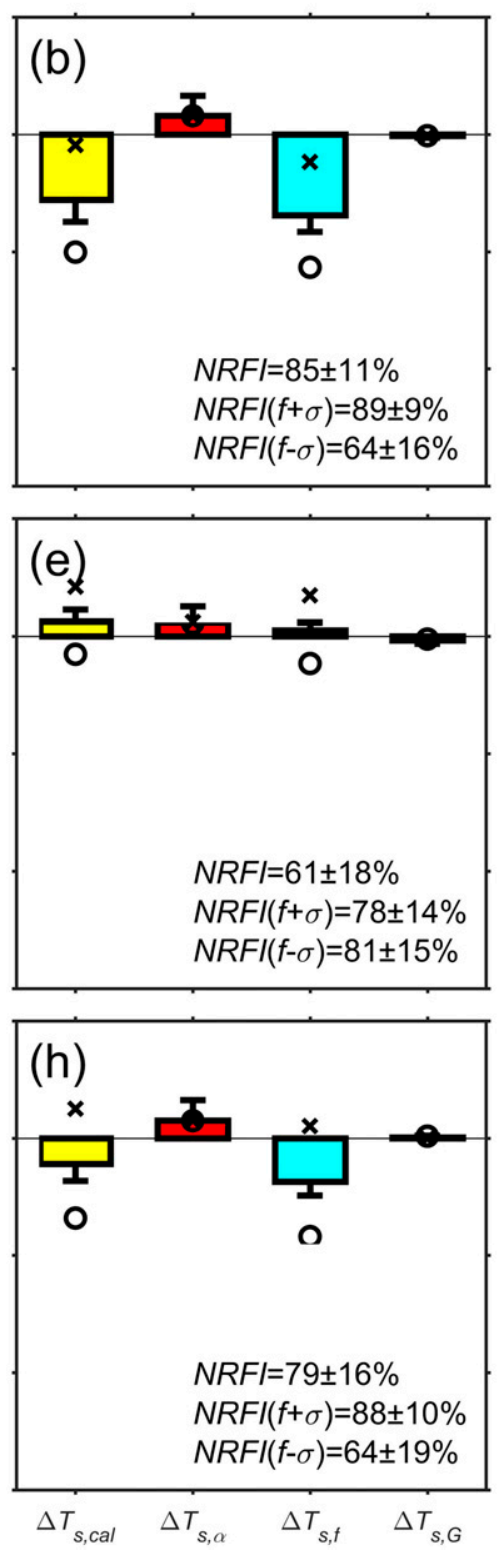

EBF
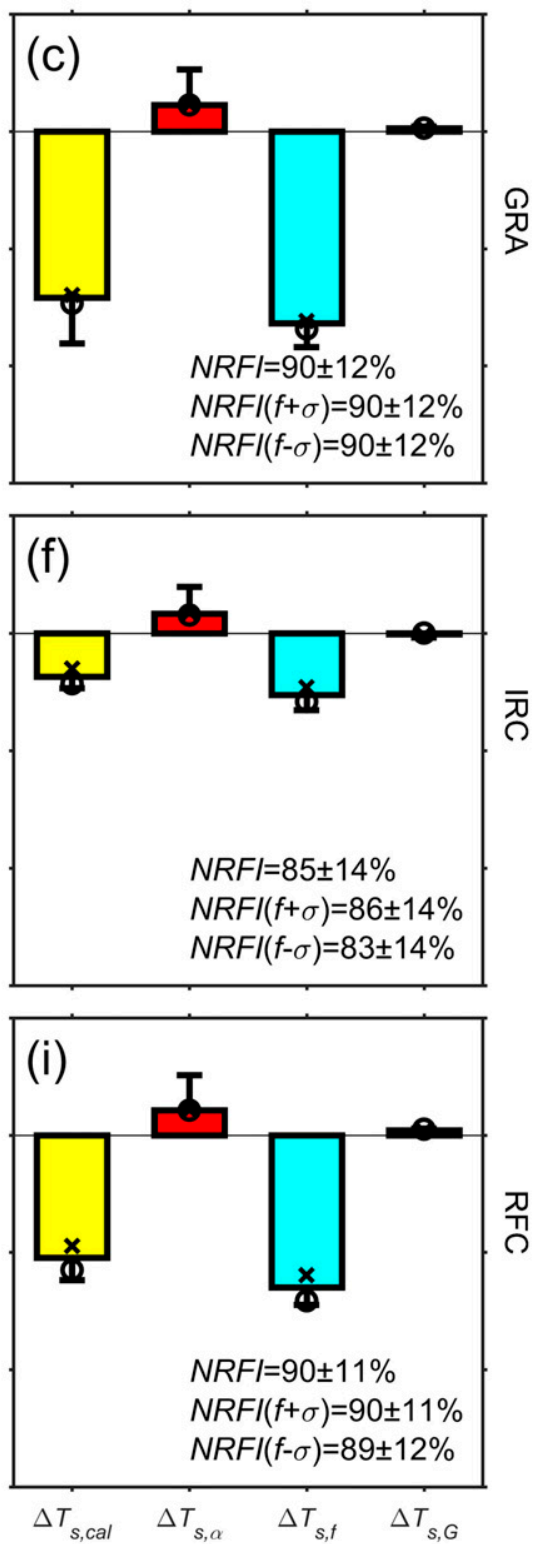

FIG. 10. Annual mean values of the calculated surface temperature change $\Delta T_{s, \text { cal }}\left({ }^{\circ} \mathrm{C}\right)$, the surface temperature change driven by albedo change $\Delta T_{s, \alpha}\left({ }^{\circ} \mathrm{C}\right)$, the surface temperature change driven by energy redistribution factor change $\Delta T_{s, f}\left({ }^{\circ} \mathrm{C}\right)$, and the surface temperature change driven by the heat storage $\Delta T_{s, G}\left({ }^{\circ} \mathrm{C}\right)$ change between forest (ENF, DBF, EBF:) and open land (GRA, IRC, RFC, forest minus open land). Changes with respect to (left) ENF, (center) DBF, and (right) EBF. Changes with respect to (a)-(c) GRA, (d)-(f) IRC, and (g)-(i) RFC. For example, (a) shows the surface temperature change between ENF and GRA. The vertical error bar denotes the standard deviation. The circle and cross represent the values achieved by plus $(f+\sigma)$ or minus $(f-\sigma)$ a standard error in the parameters utilized in the $f$ mode (see section 2$)$, respectively. The NRFI (spatial mean \pm spatial standard deviation) is provided at the bottom-right corner of each panel.

local $T_{s}$ change, indicating a dominant role in the local biophysical impact of afforestation. Our results are generally consistent with previous conclusions from in situ observations (Burakowski et al. 2018; Lee et al. 2011). For example, Lee et al. (2011) found that the $T_{s}$ bias between a grasslands site and pine and oak/hickory forest site in a temperate region of North America is attributed by $0.5^{\circ} \mathrm{C}$ from the radiative process and $-0.8^{\circ} \mathrm{C}$ from the nonradiative process. A series of previous studies (Guo et al. 2016; Wang et al. 2017) focusing on the lower reaches of Yangtze River valley over southeast China used in situ observations and also demonstrated the nonradiative effect to be larger than the radiative effect caused by LULCC. Guo et al. (2016) and Wang et al. 

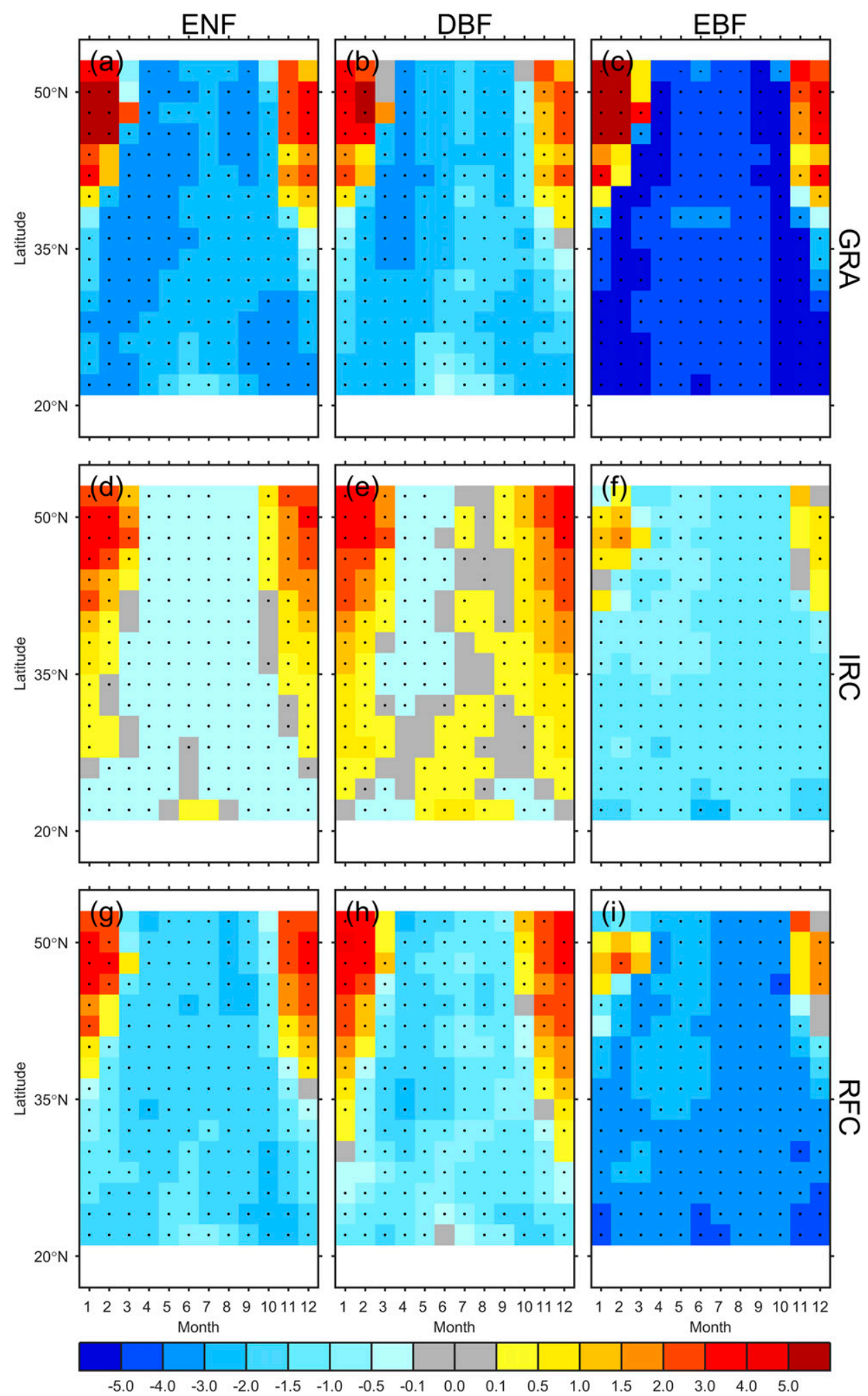

FIG. 11. Seasonal and latitudinal values of the calculated surface temperature change $\Delta T_{s, \text { cal }}\left({ }^{\circ} \mathrm{C}\right)$ between forest (ENF, DBF, EBF) and open land (GRA, IRC, RFC, forest minus open land). Changes with respect to (left) ENF, (center) DBF, and (right) EBF. Changes with respect to (a)-(c) GRA, (d)-(f) IRC, and (g)-(i) RFC. For example, (a) shows $\Delta T_{s, \text { cal }}$ between ENF and GRA. Black dots denote significance at the $95 \%$ level tested by a two-tailed Student's $t$ test. 

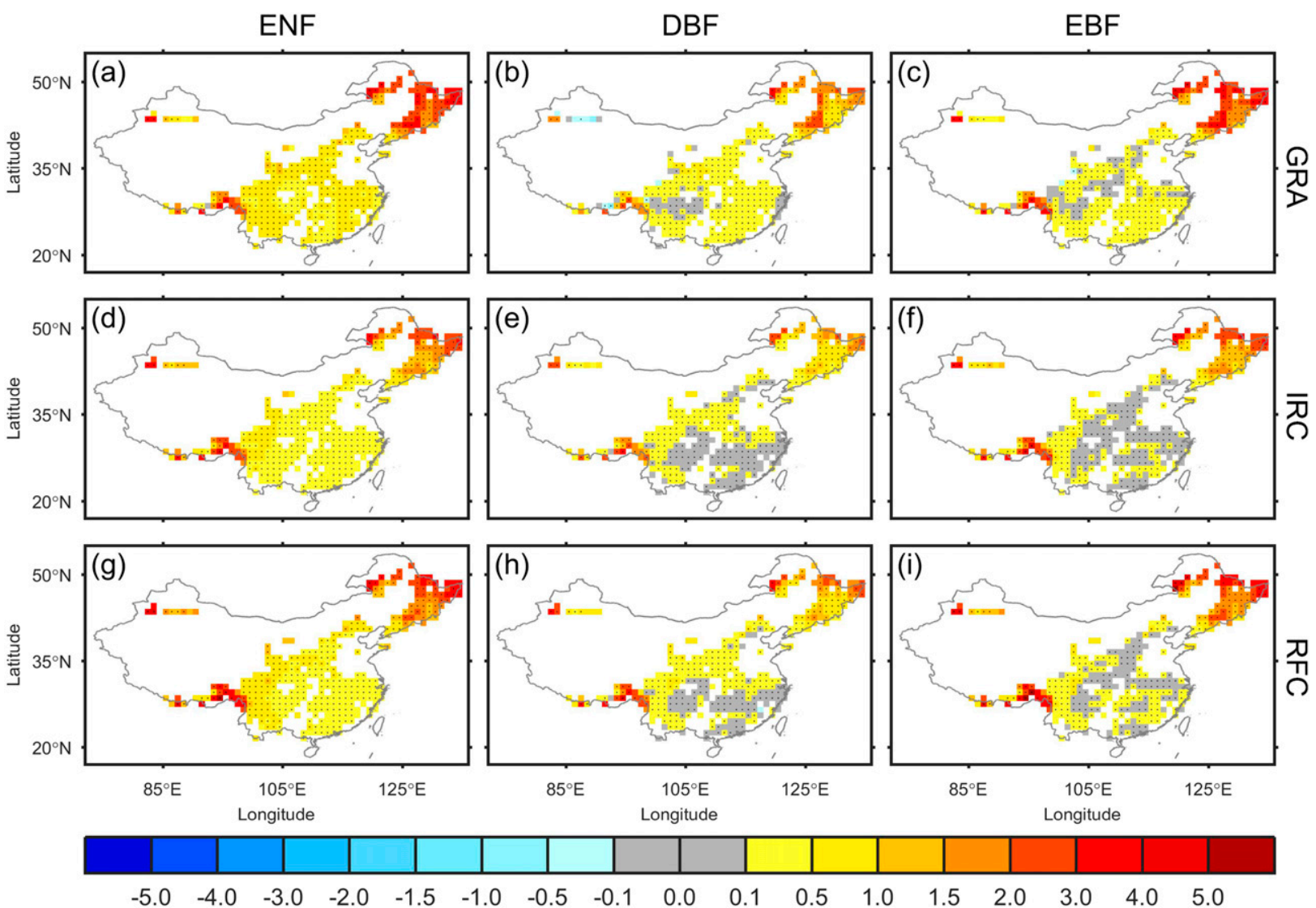

FIG. 12. Annual mean values of the surface temperature change driven by albedo change $\Delta T_{s, \alpha}\left({ }^{\circ} \mathrm{C}\right)$ between forest $(\mathrm{ENF}, \mathrm{DBF}, \mathrm{EBF})$ and open land (GRA, IRC, RFC, forest minus open land). Changes with respect to (left) ENF, (center) DBF, and (right) EBF. Changes with respect to (a)-(c) GRA, (d)-(f) IRC, and (g)-(i) RFC. For example, (a) shows $\Delta T_{s, \alpha}$ between ENF and GRA. Black dots denote significance at the $95 \%$ level tested by a two-tailed Student's $t$ test.

(2017) did not consider conversion from open land to forest due to few paired sites being available. Their findings that conversion of open land to shrubs had a larger nonradiative effect than radiative effect is consistent with our results, but likely to underestimate the nonradiative effects given that forests have larger evapotranspiration efficiencies than other land cover types. Our results are also consistent with Bright et al. (2017), who highlighted the role of the nonradiative effect of historical LULCC on local climates at the global scale. However, our estimated radiative and nonradiative effects of each conversion type are larger than those shown by Bright et al. (2017). For example, the $f$ changeinduced local $T_{s}$ change as a result of converting GRA to $\mathrm{ENF}$ in China is estimated to be about $-1.2^{\circ} \mathrm{C}$ in Bright et al. (2017) but about $-3.0^{\circ} \mathrm{C}$ in this study. It is not surprising as we used different methods and datasets and performed the calculation at a finer resolution. We also note that the IBM method may overestimate the contribution of the aerodynamic resistance by improperly assuming independence between the aerodynamic resistance and the Bowen ratio (Rigden and $\mathrm{Li}$ 2017). This would tend to overestimate the contribution of the nonradiative effects relative (which we found to dominate) compared to the radiative effects.

We compared the observed and calculated $T_{s}$ change using the IBM method combined with the $f$ model between adjacent forest and open land at continental scale. We find a discrepancy between the observed $T_{s}$ change and the calculated $T_{s}$ change, with an overestimation of the cooling effect produced by the calculated $T_{S}$ change as a whole. This bias is not surprising, and it can be explained by several factors. First of all, the accuracy of the calculated $T_{s}$ change is subjected to the limitations in the assumptions of the IBM method. For example, air temperature at a blending height within the atmospheric boundary layer is assumed to be identical between forest and open land (Lee et al. 2011). This assumption is not always met as air temperature is usually measured at a fixed height instead of the time dependent blending height, so that a term accounting for air temperature differences between forest and open land should ideally 

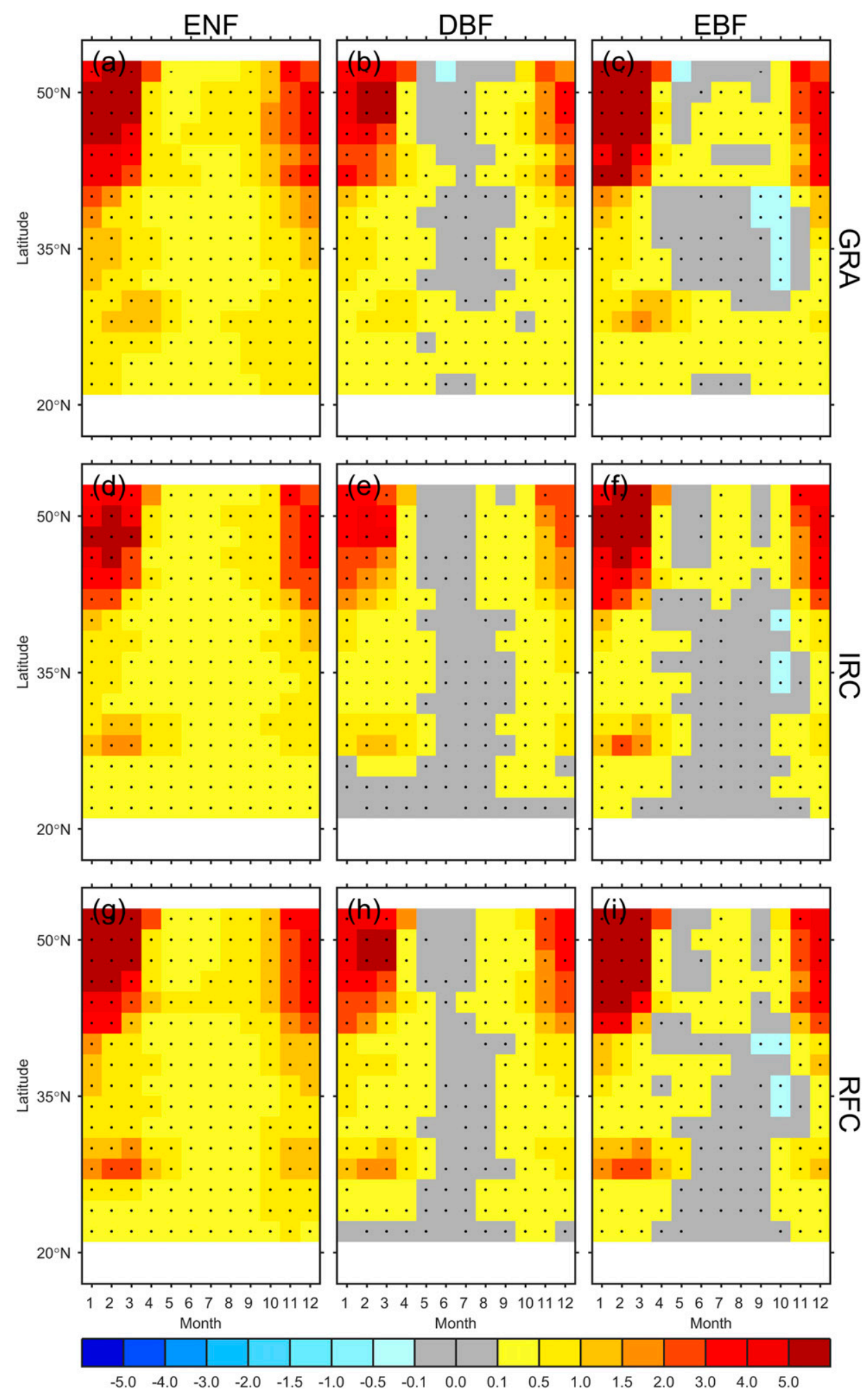

FIG. 13. Seasonal and latitudinal values of the surface temperature change driven by albedo $\Delta T_{s, \alpha}$ $\left({ }^{\circ} \mathrm{C}\right)$ change between forest $(\mathrm{ENF}, \mathrm{DBF}, \mathrm{EBF})$ and open land (GRA, IRC, RFC, forest minus open land). Changes with respect to (left) ENF, (center) DBF, and (right) EBF. Changes with respect to (a)-(c) GRA, (d)-(f) IRC, and (g)-(i) RFC. For example, (a) shows $\Delta T_{s, \alpha}$ between ENF and GRA. Black dots denote significance at the $95 \%$ level tested by a two-tailed Student's $t$ test. 

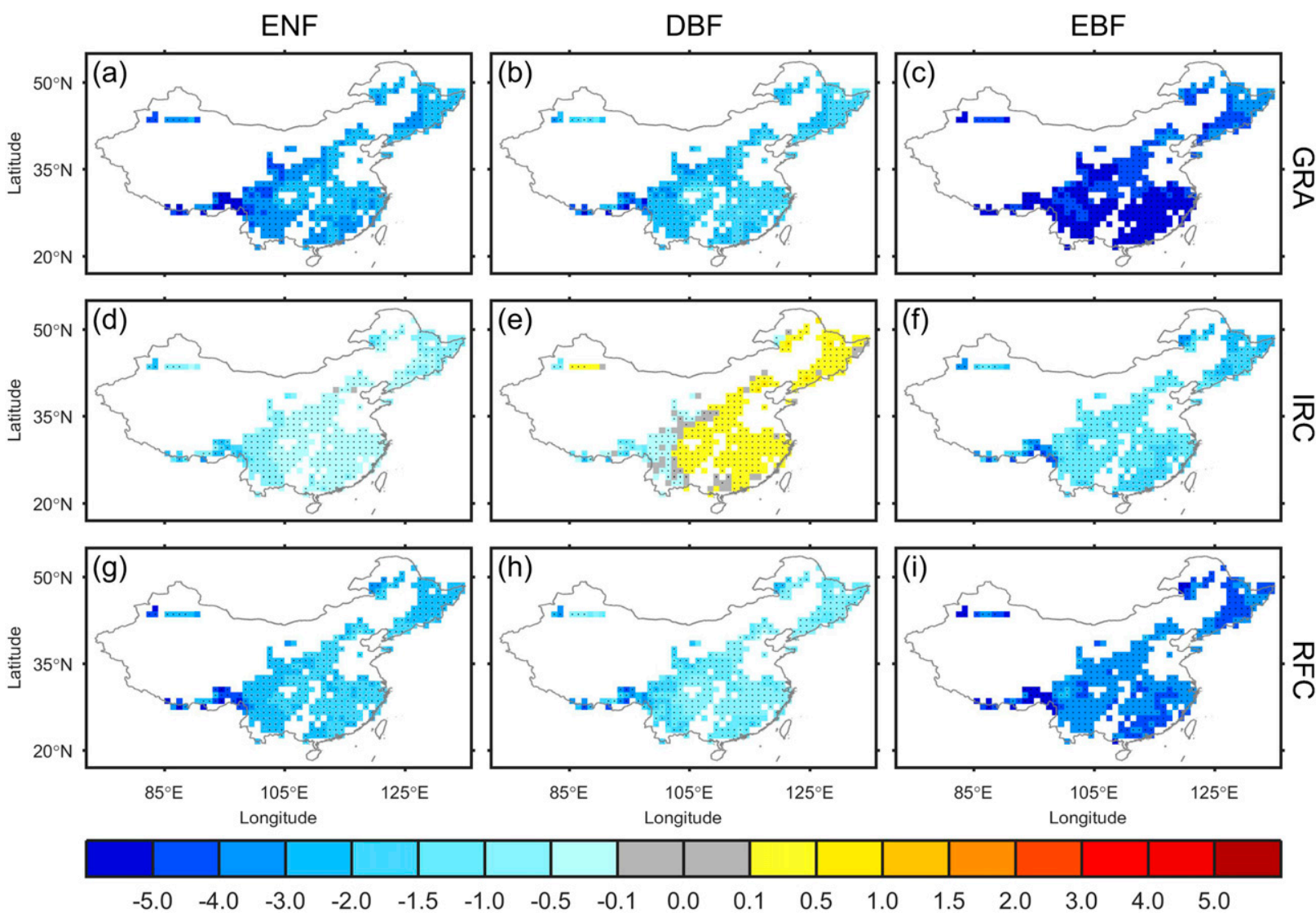

FIG. 14. Annual mean values of the surface temperature change driven by energy redistribution factor change $\Delta T_{s, f}\left({ }^{\circ} \mathrm{C}\right)$ between forest (ENF, DBF, EBF) and open land (GRA, IRC, RFC, forest minus open land). Changes with respect to (left) ENF, (center) DBF, and (right) EBF. Changes with respect to (a)-(c) GRA, (d)-(f) IRC, and (g)-(i) RFC. For example, (a) shows $\Delta T_{s, f}$ between ENF and GRA. Black dots denote significance at the 95\% level tested by a two-tailed Student's $t$ test.

be included (Burakowski et al. 2018; Wang et al. 2018). Moreover, a linearization of surface upward longwave radiation in the formulation of $f$ can also cause a bias in the calculated $T_{s}$, and this bias tends to be larger when the $f$ difference between forest and open land increases (Bright et al. 2017). Second, the calculated $T_{s}$ change can be impacted by the uncertainty in the estimated parameters employed in the $f$ model. Larger uncertainty mainly occurs when open land is converted to DBF, in which case the $T_{s}$ change driven by $f$ change is strongly sensitive to the parameters used in the $f$ model. Third, the observed $T_{s}$ change represents the impact of afforestation under clear-sky condition as $T_{s}$ is best retrieved by satellite in cloud-free conditions. In contrast the calculated $T_{s}$ change includes the both impact of afforestation under clear-sky and cloudy conditions. Fourthly, we note a large bias between the observed and the calculated $T_{s}$ change in southwest China. This bias may be associated with the complex terrain although these areas are unlikely to be prioritized for afforestation. Finally, the observed $T_{s}$ change as a result of afforestation is more spatially heterogeneous than the calculated $T_{s}$ change. This is hint that the calculated $T_{s}$ change is likely not to sufficiently account for variability in biophysical parameters (e.g., soil hydraulic conductivity) that affect energy exchange.

We used satellite observations with a goal of filling the gap between in situ observations and model simulations. However, there are caveats that need to be considered when comparing our results with the result from climate model. The most critical question we should consider is the fairness of comparing the space-for-time method based result with the climate model based result. First, the space-for-time method assumes the adjacent sites or pixels share an equivalent background climate (e.g., downward shortwave and longwave radiation), suggesting the atmospheric feedbacks to LULCC are ignored. However, LULCC can affect local temperature indirectly through a feedback from atmosphere (Chen and Dirmeyer 2016; Devaraju et al. 2018; van der Molen 

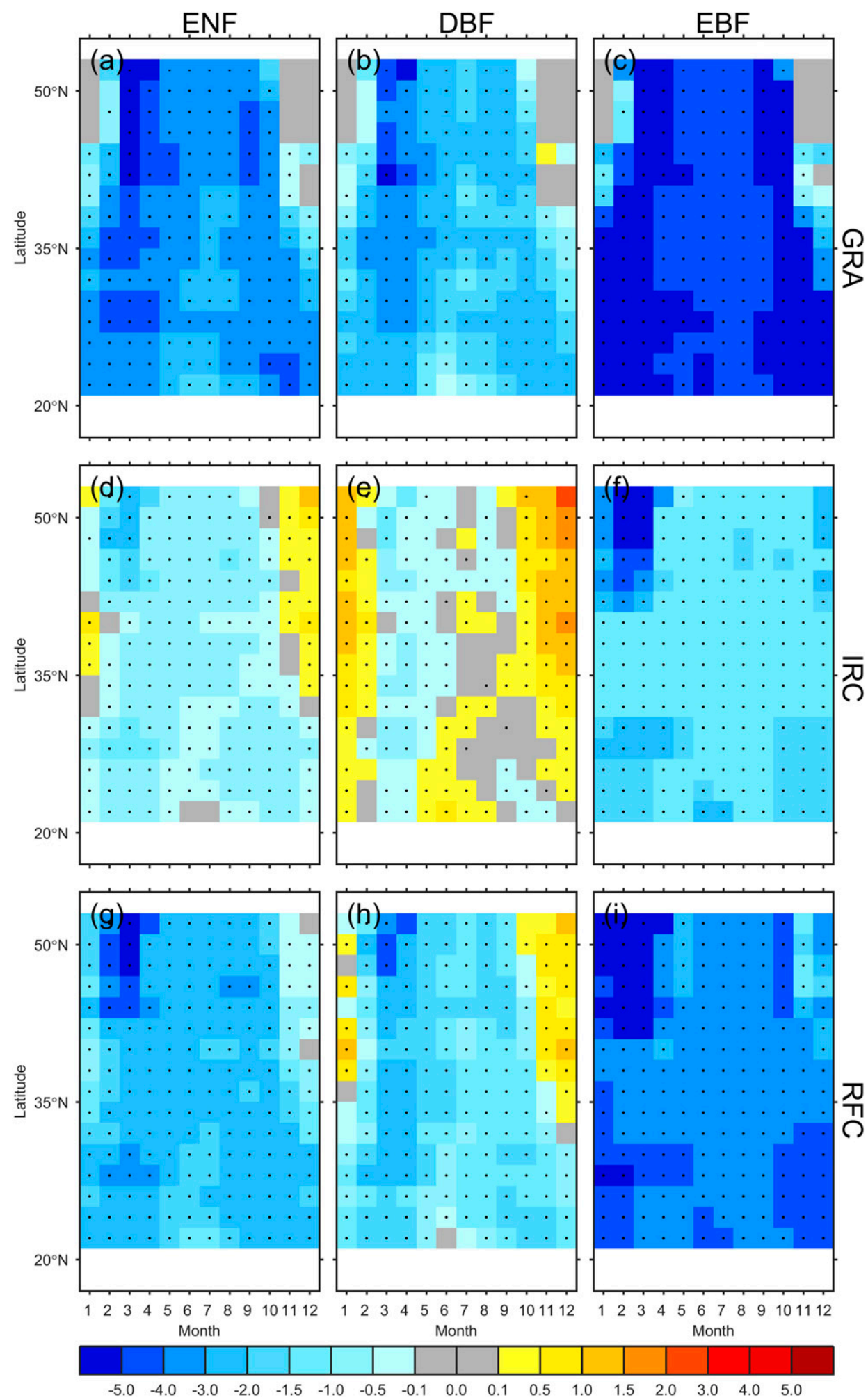

FIG. 15. Seasonal and latitudinal values of the surface temperature change driven by energy redistribution factor change $\Delta T_{s, f}\left({ }^{\circ} \mathrm{C}\right)$ between forest $(\mathrm{ENF}, \mathrm{DBF}, \mathrm{EBF})$ and open land (GRA, IRC, RFC, forest minus open land). Changes with respect to (left) ENF, (center) DBF, and (right) EBF. Changes with respect to (a)-(c) GRA, (d)-(f) IRC, and (g)-(i) RFC. For example, (a) shows $\Delta T_{s, f}$ between ENF and GRA. Black dots denote significance at the $95 \%$ level tested by a two-tailed Student's $t$ test. 

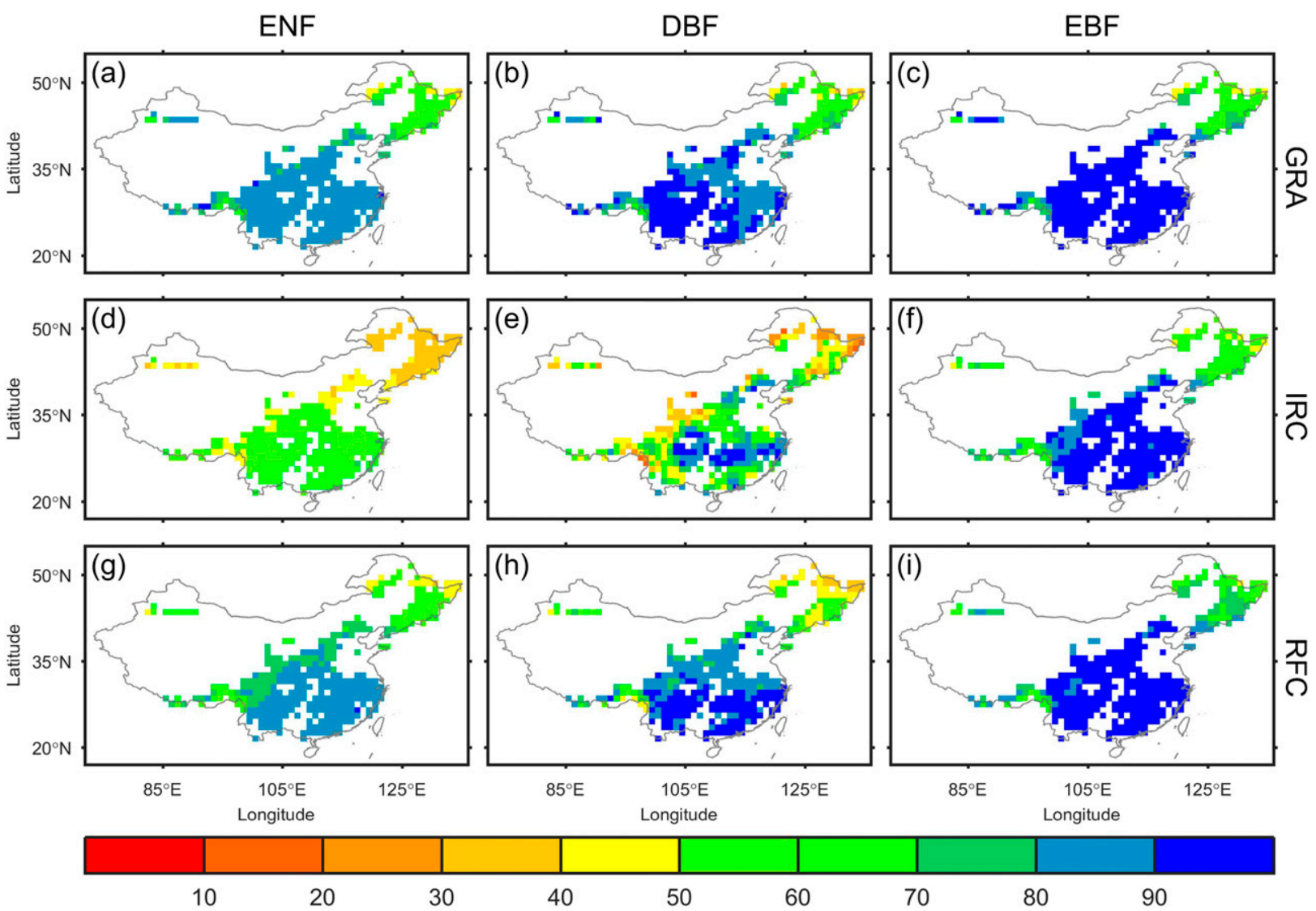

FIG. 16. Annual mean values of the NRFI (\%) between forest (ENF, DBF, EBF) and open land (GRA, IRC, RFC, forest minus open land). Changes with respect to (left) ENF, (center) DBF, and (right) EBF. Changes with respect to (a)-(c) GRA, (d)-(f) IRC, and (g)-(i) RFC. For example, (a) shows the NRFI between ENF and GRA.

et al. 2011; Xu et al. 2015). For example, afforestation causes an increase in surface evapotranspiration, which in turn tends to increase atmospheric water vapor and cloudiness formation. The higher water vapor and cloud cover increase downward longwave radiation, which warms $T_{s}$, and simultaneously decrease downward shortwave radiation and cool $T_{s}$. Second, Winckler et al. (2017) further demonstrated that in the climate model LULCC could robustly affect the surface temperature of neighboring grids through nonlocal effects with the radiative process having a larger nonlocal effect than the local effect in temperate regions; these nonlocal effects are also ignored in the space-for-time method based results. Third, as the $T_{s}$ can only be measured by satellite when cloud is absent, the observed $T_{s}$ change based on satellite observation to be more precisely reflects the impact of afforestation under clear-sky conditions. As a result, comparing the space-for-time method based results with coupled model simulations is therefore a challenge as these boundary layer feedbacks are explicitly considered in climate models (Boisier et al. 2012;
Davin and de Noblet-Ducoudré 2010; Devaraju et al. 2018). Also, care needs to be taken in assuming that results for $T_{s}$ can be extrapolated to $T_{a}$. While $T_{a}$ depends on $T_{s}$, it is affected by other factors such as atmospheric conditions including air advection, implying that $T_{s}$ is more sensitive to LULCC than $T_{a}$ (Alkama and Cescatti 2016; Li et al. 2015; Luyssaert et al. 2014; Meier et al. 2018). It is also demonstrated in Winckler et al. (2018) that near-surface air temperature is affected by the local effects of LULCC only about half as much compared to surface temperature in climate models. Thus, which temperature is chosen should be carefully taken into consideration when comparing observation and modeling based results.

There are some ways to take our analysis further. For example, our analysis is mainly performed on monthly and annual time scales, suggesting that the characteristics of the local $T_{s}$ change in response to afforestation at finer time scales cannot be identified here. Increasing in situ studies (Burakowski et al. 2018; Lee et al. 2011; Wang et al. 2018) and satellite observations ( $\mathrm{Li}$ et al. 
2015; Peng et al. 2014; Schultz et al. 2017) have further demonstrated the diurnal asymmetry of the surface temperature in response to afforestation. In contrast to the strong cooling effect of forest in daytime, forest tends to warm the surface temperature compared to open land in nighttime because of strong turbulence of forest, which brings heat from aloft to surface during stable atmospheric conditions combined with the release of heat stored in daytime (Lee et al. 2011; Schultz et al. 2017; Peng et al. 2014). Thus the radiative and nonradiative effects of afforestation on local $T_{s}$ function differently in daytime and nighttime (Lee et al. 2011; Wang et al. 2018). At this finer time scale, the soil heat storage change induced nonradiative effect even plays a considerable role in driving local $T_{s}$ in both daytime and nighttime (Lee et al. 2011; Wang et al. 2018). Thus, the attribution of afforestation-induced $T_{s}$ changes to radiative and nonradiative effects in daytime and nighttime separately at continental scale needs further investigation. Our analysis is built upon single snapshots in time of $T_{s}$ (1030 and 2230 LT for Terra and 0130 and 1330 LT for Aqua), averaged over a month, as opposed to a full diurnal analysis. Our analysis would not therefore accurately estimate the precise magnitude of the cooling induced by afforestation. The magnitude of the calculated $T_{s}$ change when switching between GRA and $\operatorname{EBF}\left(-4.35^{\circ} \pm 1.15^{\circ} \mathrm{C}\right)$ is such large that further analysis is now warranted in this space to capture the full temporal impact of cooling. This gap in our knowledge might be addressed through a combination of diurnal $T_{s}$ measurements and mobile eddy-covariance measurements of $Q_{E}$.

Our results reveal that the relative importance of the radiative and nonradiative effects varies with forest type, a result of value to policy makers focused on mitigation strategies. In terms of local $T_{s}$, afforestation of GRA and RFC by planting EBF is most beneficial, but afforestation with both DBF and ENF may also lead to cooling. Little benefit can be achieved from converting IRC to DBF or ENF. Given challenges associated with food production, afforestation of RFC is unlikely to be feasible on a large scale. This suggests that targeting GRA with afforestation with EBF is a reasonable strategy to locally mitigate climate warming where possible, with afforestation using DBF and ENF also being beneficial. Afforestation of IRC has little positive benefit on cooling temperatures and is infeasible on a large scale due to the need to feed China's growing population. In addition, as the forest cools surface temperature by transpiring more water, reforestation adds additional risk to the resilience of local and regional water resources. The adaptation of planted forests to the local climate including water availability and energy demands necessary for tree growth and the local environment including soil conditions is also not fully accounted for here, although we do map the local surface temperature change driven by all conversion types over mainland China. For example, the energy and water demands of EBF make it unsuitable in more northern latitudes or higher-altitude regions. Thus, the large cooling effect achieved by converting open land to EBF in those growth unsuitable regions should be interpreted as a sensitivity study, not as a feasible mitigation option. In the northern arid and semiarid regions where the extreme high temperature risk is small but the water supply is limited, afforestation probably exacerbates any water deficit (Cao et al. 2011; Chen et al. 2015; Feng et al. 2016). As a result, large-scale afforestation programs must be aligned with local conditions, and total water usage may be an important consideration when weighing the benefits of one tree functional type over another in any afforestation strategy. Prioritizing afforestation in regions that were formerly forest rather than naturally grasslands could be most beneficial to avoid negative effects of climate and water availability (Cao et al. 2011; Fu et al. 2017; Jian et al. 2015).

\section{Conclusions}

Using satellite observations between 2001 and 2012, we have investigated the local biophysical effects of afforestation in China. A novel aspect of our study is that we quantify the radiative and nonradiative effects of afforestation on local surface temperature at continental scales based on space-for-time method combined with the Intrinsic Biophysical Mechanism (IBM) method. We find that the forest has a smaller albedo $(2.63 \% \pm$ $2.72 \%)$ and a larger leaf area index $\left(0.70 \pm 0.37 \mathrm{~m}^{2} \mathrm{~m}^{-2}\right)$, and subsequently a larger energy redistribution factor than open land averaged over colored grid cells. The increased absorbed radiative energy tends to be more easily dissipated via latent heat $\left(4.91 \pm 5.20 \mathrm{~W} \mathrm{~m}^{-2}\right)$ rather than sensible heat $\left(0.49 \pm 7.00 \mathrm{~W} \mathrm{~m}^{-2}\right)$ over the forest compared with open land. As a result, the impact of afforestation on the annual mean local $T_{s}$ change is observed to be $-0.32^{\circ} \mathrm{C}\left( \pm 0.37^{\circ} \mathrm{C}\right)$, while the local $T_{s}$ change in response to afforestation is calculated to be $-0.53^{\circ} \mathrm{C}\left( \pm 0.48^{\circ} \mathrm{C}\right)$. Radiative processes cause local warming of $0.23^{\circ} \mathrm{C}\left( \pm 0.21^{\circ} \mathrm{C}\right)$ over paired-site regions. However, the majority $(79 \% \pm 0.16 \%)$ of the changes in temperature over afforested regions are associated with nonradiative processes which explain local cooling of $-0.74^{\circ} \pm 0.50^{\circ} \mathrm{C}$. We have also demonstrated that the nonradiative effect varies with the forest and open land types with the largest cooling achieved by replacing GRA or RFC with evergreen tree types such EBF or ENF. In 
contrast, converting IRC with ENF and DBF could even warm local surface temperature, suggesting that the improper choice of conversion types may risk of aggravating local temperature increases. Thus our study further highlights the necessary of considering local biophysical impact in the case of afforestation. It also provides valuable information in the perspective of local temperature for the policy makers who plan to expand the afforestation program over China in the future. We caution that food security, water resources, and the adaptation of the planted trees also need to be taken into account as implementation of large-scale afforestation is considered.

Acknowledgments. This research is supported by the National Key Research and Development Program of China (2017YFA0603803), the Natural Science Foundation of China (41775075, 41475063), and the Jiangsu Collaborative Innovation Center for Climate Change. This work is also supported by the Australian Research Council (ARC) via the ARC Centre of Excellence for Climate Extremes (CE170100023). J.G. gratefully acknowledges financial support from China Scholarship Council. M.D.K. acknowledges support from the Australian Research Council Centre of Excellence for Climate Extremes (CE170100023) and the New South Wales Research Attraction and Acceleration Program. We thank Dr. Feng Gao of ARS, USDA, Beltsville, Maryland, USA, who provided the climatological albedo look-up maps. We also appreciate three anonymous reviewers for their constructive and valuable suggestions for the great improvements to the manuscript. The MODIS land cover type (MCD12C1 and MCD12Q1), land surface temperature (MOD11C3 and MYD11C3), and albedo (MCD43C3) products are retrieved from https:// lpdaac.usgs.gov, maintained by the NASA EOSDIS Land Processes Distributed Active Archive Center (LP DAAC) at the USGS Earth Resources Observation and Science (EROS) Center, Sioux Falls, South Dakota. The evapotranspiration (MOD16A) product is downloaded from http://files.ntsg.umt.edu/data/NTSG_ Products/MOD16/. The area equipped for irrigation is from Historical Irrigation Data, https://mygeohub.org/ publications/8/2. SRTM30 DEM data are available from the U.S. Geological Survey, https://dds.cr.usgs.gov/srtm/ version2_1/SRTM30/. The ITPCAS meteorological forcing dataset is developed by the Data Assimilation and Modeling Center for Tibetan Multi-spheres, Institute of Tibetan Plateau Research, Chinese Academy of Sciences, http://westdc.westgis.ac.cn/. The GLASS albedo and LAI product is from Global Land Cover Facility, http:// glcf.umd.edu/.

\section{REFERENCES}

Alkama, R., and A. Cescatti, 2016: Biophysical climate impacts of recent changes in global forest cover. Science, 351, 600-604, https://doi.org/10.1126/science.aac8083.

Anderson, R. G., and Coauthors, 2011: Biophysical considerations in forestry for climate protection. Front. Ecol. Environ., 9, 174-182, https://doi.org/10.1890/090179.

Arora, V. K., and A. Montenegro, 2011: Small temperature benefits provided by realistic afforestation efforts. Nat. Geosci., $\mathbf{4}$, 514-518, https://doi.org/10.1038/ngeo1182.

Avila, F. B., A. J. Pitman, M. G. Donat, L. V. Alexander, and G. Abramowitz, 2012: Climate model simulated changes in temperature extremes due to land cover change. J. Geophys. Res., 117, D04108, https://doi.org/10.1029/2011JD016382.

Bala, G., K. Caldeira, M. Wickett, T. J. Phillips, D. B. Lobell, C. Delire, and A. Mirin, 2007: Combined climate and carbon-cycle effects of large-scale deforestation. Proc. Natl. Acad. Sci. USA, 104, 6550-6555, https://doi.org/10.1073/ pnas.0608998104.

Boisier, J. P., and Coauthors, 2012: Attributing the impacts of landcover changes in temperate regions on surface temperature and heat fluxes to specific causes: Results from the first LUCID set of simulations. J. Geophys. Res., 117, D12116, https:// doi.org/10.1029/2011JD017106.

Bonan, G. B., 2008: Forests and climate change: Forcings, feedbacks, and the climate benefits of forests. Science, 320, 1444 1449, https://doi.org/10.1126/science.1155121.

Bright, R. M., K. Zhao, R. B. Jackson, and F. Cherubini, 2015: Quantifying surface albedo and other direct biogeophysical climate forcings of forestry activities. Global Change Biol., 21, 3246-3266, https://doi.org/10.1111/gcb.12951.

—, E. Davin, T. O'Halloran, J. Pongratz, K. Zhao, and A. Cescatti, 2017: Local temperature response to land cover and management change driven by non-radiative processes. Nat. Climate Change, 7, 296-302, https://doi.org/10.1038/ nclimate 3250 .

Bryan, B. A., and Coauthors, 2018: China's response to a national land-system sustainability emergency. Nature, 559, 193-204, https://doi.org/10.1038/s41586-018-0280-2.

Burakowski, E., A. Tawfik, A. Ouimette, L. Lepine, K. Novick, S. Ollinger, C. Zarzycki, and G. Bonan, 2018: The role of surface roughness, albedo, and Bowen ratio on ecosystem energy balance in the eastern United States. Agric. For. Meteor., 249, 367-376, https://doi.org/10.1016/j.agrformet.2017.11.030.

Canadell, J. G., and M. R. Raupach, 2008: Managing forests for climate change mitigation. Science, 320, 1456-1457, https:// doi.org/10.1126/science.1155458.

Cao, S., L. Chen, D. Shankman, C. Wang, X. Wang, and H. Zhang, 2011: Excessive reliance on afforestation in China's arid and semiarid regions: Lessons in ecological restoration. Earth-Sci. Rev., 104, 240-245, https://doi.org/10.1016/j.earscirev.2010.11.002.

Chen, C., and Coauthors, 2019: China and India lead in greening of the world through land-use management. Nature Sustainability, 2, 122-129, https://doi.org/10.1038/s41893-019-0220-7.

Chen, L., and P. A. Dirmeyer, 2016: Adapting observationally based metrics of biogeophysical feedbacks from land cover/ land use change to climate modeling. Environ. Res. Lett., 11, 034002, https://doi.org/10.1088/1748-9326/11/3/034002.

Chen, X., Z. Su, Y. Ma, J. Cleverly, and M. Liddell, 2017: An accurate estimate of monthly mean land surface temperatures from MODIS clear-sky retrievals. J. Hydrometeor., 18, $2827-$ 2847, https://doi.org/10.1175/JHM-D-17-0009.1. 
Chen, Y., K. Wang, Y. Lin, W. Shi, Y. Song, and X. He, 2015: Balancing green and grain trade. Nat. Geosci., 8, 739-741, https://doi.org/10.1038/ngeo2544.

Davin, E. L., and N. de Noblet-Ducoudré, 2010: Climatic impact of global-scale deforestation: Radiative versus nonradiative processes. J. Climate, 23, 97-112, https://doi.org/10.1175/ 2009JCLI3102.1.

Devaraju, N., N. de Noblet-Ducoudré, B. Quesada, and G. Bala, 2018: Quantifying the relative importance of direct and indirect biophysical effects of deforestation on surface temperature and teleconnections. J. Climate, 31, 3811-3829, https:// doi.org/10.1175/JCLI-D-17-0563.1.

Duveiller, G., J. Hooker, and A. Cescatti, 2018: The mark of vegetation change on Earth's surface energy balance. Nat. Commun., 9, 679, https://doi.org/10.1038/s41467-017-02810-8.

Feng, X., and Coauthors, 2016: Revegetation in China's Loess Plateau is approaching sustainable water resource limits. Nat. Climate Change, 6, 1019-1022, https://doi.org/10.1038/nclimate3092.

Findell, K. L., A. Berg, P. Gentine, J. P. Krasting, B. R. Lintner, S. Malyshev, J. A. Santanello, and E. Shevliakova, 2017: The impact of anthropogenic land use and land cover change on regional climate extremes. Nat. Commun., 8, 989, https:// doi.org/10.1038/s41467-017-01038-w.

Friedl, M. A., D. Sulla-Menashe, B. Tan, A. Schneider, N. Ramankutty, A. Sibley, and X. M. Huang, 2010: MODIS Collection 5 global land cover: Algorithm refinements and characterization of new datasets. Remote Sens. Environ., 114, 168-182, https://doi.org/10.1016/j.rse.2009.08.016.

Fu, B., S. Wang, Y. Liu, J. Liu, W. Liang, and C. Miao, 2017: Hydrogeomorphic ecosystem responses to natural and anthropogenic changes in the Loess Plateau of China. Annu. Rev. Earth Planet. Sci., 45, 223-243, https://doi.org/10.1146/ annurev-earth-063016-020552.

Gao, F., T. He, Z. Wang, B. Ghimire, Y. Shuai, J. Masek, C. Schaaf, and C. Williams, 2014: Multiscale climatological albedo look-up maps derived from moderate resolution imaging spectroradiometer BRDF/albedo products. J. Appl. Remote Sens., 8, 083532 , https://doi.org/10.1117/1.JRS.8.083532.

Ghimire, B., C. A. Williams, J. Masek, F. Gao, Z. Wang, C. Schaaf, and T. He, 2014: Global albedo change and radiative cooling from anthropogenic land cover change, 1700 to 2005 based on MODIS, land use harmonization, radiative kernels, and reanalysis. Geophys. Res. Lett., 41, 9087-9096, https://doi.org/ 10.1002/2014GL061671.

Guo, W., X. Wang, J. Sun, A. Ding, and J. Zou, 2016: Comparison of land-atmosphere interaction at different surface types in the mid- to lower reaches of the Yangtze River valley. Atmos. Chem. Phys., 16, 9875-9890, https://doi.org/10.5194/acp-16-9875-2016.

Hall, D. K., and G. A. Riggs, 2015: MODIS/Terra Snow Cover Monthly L3 Global 0.05 Deg CMG, Version 6 [MOD10CM and MYD10CM]. NASA National Snow and Ice Data Center Distributed Active Archive Center, accessed 15 March 2017, https://doi.org/10.5067/MODIS/MOD10CM.006.

Hua, W., and Coauthors, 2017: Observational quantification of climatic and human influences on vegetation greening in China. Remote Sens., 9, 425, https://doi.org/10.3390/rs9050425.

Jackson, R. B., and Coauthors, 2008: Protecting climate with forests. Environ. Res. Lett., 3, 044006, https://doi.org/10.1088/ 1748-9326/3/4/044006.

Jian, S., C. Zhao, S. Fang, and K. Yu, 2015: Effects of different vegetation restoration on soil water storage and water balance in the Chinese Loess Plateau. Agric. For. Meteor., 206, 85-96, https://doi.org/10.1016/j.agrformet.2015.03.009.
Juang, J. Y., G. Katul, M. Siqueira, P. Stoy, and K. Novick, 2007: Separating the effects of albedo from eco-physiological changes on surface temperature along a successional chronosequence in the southeastern United States. Geophys. Res. Lett., 34, L21408, https://doi.org/10.1029/2007GL031296.

Lee, X., and Coauthors, 2011: Observed increase in local cooling effect of deforestation at higher latitudes. Nature, 479, 384387, https://doi.org/10.1038/nature10588.

Li, X., and Coauthors, 2008: Cryospheric change in China. Global Planet. Change, 62, 210-218, https://doi.org/10.1016/ j.gloplacha.2008.02.001.

_ - H. Chen, J. Wei, W. Hua, S. Sun, H. Ma, X. Li, and J. Li, 2018: Inconsistent responses of hot extremes to historical land use and cover change among the selected CMIP5 models. J. Geophys. Res. Atmos., 123, 3497-3512, https://doi.org/10.1002/2017JD028161.

Li, Y., M. Zhao, S. Motesharrei, Q. Mu, E. Kalnay, and S. Li, 2015: Local cooling and warming effects of forests based on satellite observations. Nat. Commun., 6, 6603, https://doi.org/10.1038/ ncomms7603.

Liang, S., and Q. Liu, 2012: Global Land Surface Products: Albedo Product Data Collection (1985-2010). Beijing Normal University, accessed 15 March 2018, https://doi.org/10.6050/ glass863.3001.db.

_ Index Product Data Collection (1985-2010). Beijing Normal University, accessed 15 March 2018, https://doi.org/10.6050/ glass863.3004.db.

Liu, J., S. Li, Z. Ouyang, C. Tam, and X. Chen, 2008: Ecological and socioeconomic effects of China's policies for ecosystem services. Proc. Natl. Acad. Sci. USA, 105, 9477-9482, https:// doi.org/10.1073/pnas.0706436105.

Liu, X., X. Zhu, S. Li, Y. Liu, and Y. Pan, 2015: Changes in growing season vegetation and their associated driving forces in China during 2001-2012. Remote Sens., 7, 15 517-15 535, https:// doi.org/10.3390/rs71115517.

Luyssaert, S., and Coauthors, 2014: Land management and landcover change have impacts of similar magnitude on surface temperature. Nat. Climate Change, 4, 389-393, https://doi.org/ 10.1038/nclimate2196.

Ma, D., M. Notaro, Z. Liu, G. Chen, and Y. Liu, 2013: Simulated impacts of afforestation in East China monsoon region as modulated by ocean variability. Climate Dyn., 41, 2439-2450, https://doi.org/10.1007/s00382-012-1592-9.

Ma, W., G. Jia, and A. Zhang, 2017: Multiple satellite-based analysis reveals complex climate effects of temperate forests and related energy budget. J. Geophys. Res. Atmos., 122, 3806-3820, https://doi.org/10.1002/2016JD026278.

Meier, R., and Coauthors, 2018: Evaluating and improving the Community Land Model's sensitivity to land cover. Biogeosciences, 15, 4731-4757, https://doi.org/10.5194/bg-154731-2018.

Monteith, J. L., 1975: Principles. Vol. 1, Vegetation and the Atmosphere, Academic Press, 278 pp.

Mu, Q., M. Zhao, and S. W. Running, 2011: Improvements to a MODIS global terrestrial evapotranspiration algorithm. Remote Sens. Environ., 115, 1781-1800, https://doi.org/10.1016/ j.rse.2011.02.019.

Pacala, S., and R. Socolow, 2004: Stabilization wedges: Solving the climate problem for the next 50 years with current technologies. Science, 305, 968-972, https://doi.org/10.1126/science.1100103.

Peng, S., and Coauthors, 2014: Afforestation in China cools local land surface temperature. Proc. Natl. Acad. Sci. USA, 111, 2915-2919, https://doi.org/10.1073/pnas.1315126111. 
Perugini, L., L. Caporaso, S. Marconi, A. Cescatti, B. Quesada, N. de Noblet-Ducoudré, J. I. House, and A. Arneth, 2017: Biophysical effects on temperature and precipitation due to land cover change. Environ. Res. Lett., 12, 053002, https:// doi.org/10.1088/1748-9326/aa6b3f.

Piao, S., and Coauthors, 2015: Detection and attribution of vegetation greening trend in China over the last 30 years. Global Change Biol., 21, 1601-1609, https://doi.org/10.1111/gcb.12795.

Pitman, A. J., and Coauthors, 2009: Uncertainties in climate responses to past land cover change: First results from the LUCID intercomparison study. Geophys. Res. Lett., 36, L14814, https://doi.org/10.1029/2009GL039076.

— and Coauthors, 2012: Effects of land cover change on temperature and rainfall extremes in multi-model ensemble simulations. Earth Syst. Dyn., 3, 213-231, https://doi.org/10.5194/esd-3-213-2012.

Rigden, A., and D. Li, 2017: Attribution of surface temperature anomalies induced by land use and land cover changes. Geophys. Res. Lett., 44, 6814-6822, https://doi.org/10.1002/2017GL073811.

Rotenberg, E., and D. Yakir, 2010: Contribution of semi-arid forests to the climate system. Science, 327, 451-454, https:// doi.org/10.1126/science.1179998.

Running, S. W., Q. Mu, M. Zhao, and A. Moreno, 2017: User's Guide MODIS Global Terrestrial Evapotranspiration (ET) Product (NASA MOD16A2/A3) NASA Earth Observing System MODIS Land Algorithm, accessed 15 March 2018, http://www.ntsg.umt.edu/project/modis/mod16.php.

Schultz, N. M., P. J. Lawrence, and X. Lee, 2017: Global satellite data highlights the diurnal asymmetry of the surface temperature response to deforestation. J. Geophys. Res. Biogeosci., 122, 903-917, https://doi.org/10.1002/2016JG003653.

Siebert, S., M. Kummu, M. Porkka, P. Döll, N. Ramankutty, and B. R. Scanlon, 2015: A global data set of the extent of irrigated land from 1900 to 2005. Hydrol. Earth Syst. Sci., 19, 1521-1545, https://doi.org/10.5194/hess-19-1521-2015.

Skinner, C. B., C. J. Poulsen, and J. S. Mankin, 2018: Amplification of heat extremes by plant $\mathrm{CO}_{2}$ physiological forcing. Nat . Commun., 9, 1094, https://doi.org/10.1038/s41467-018-03472-w.

Teuling, A. J., and Coauthors, 2010: Contrasting response of European forest and grassland energy exchange to heatwaves. Nat. Geosci., 3, 722-727, https://doi.org/10.1038/ngeo950.

van der Molen, M. K., B. J. J. M. van den Hurk, and W. Hazeleger, 2011: A dampened land use change climate response towards the tropics. Climate Dyn., 37, 2035-2043, https://doi.org/ 10.1007/s00382-011-1018-0.

Wan, Z., 2014: New refinements and validation of the Collection-6 MODIS land-surface temperature/emissivity product. Remote Sens. Environ., 140, 36-45, https://doi.org/10.1016/j.rse. 2013.08.027

Wang, L., and Coauthors, 2018: Response of surface temperature to afforestation in the Kubuqi Desert, Inner Mongolia. J. Geophys. Res., 123, 948-964, https://doi.org/10.1002/2017JD027522.

Wang, X., W. Guo, B. Qiu, Y. Liu, J. Sun, and A. Ding, 2017: Quantifying the contribution of land use change to surface temperature in the lower reaches of the Yangtze River. Atmos. Chem. Phys., 17, 4989-4996, https://doi.org/10.5194/acp-17-4989-2017.

Winckler, J., C. H. Reick, and J. Pongratz, 2017: Robust identification of local biogeophysical effects of land-cover change in a global climate model. J. Climate, 30, 1159-1176, https:// doi.org/10.1175/JCLI-D-16-0067.1.

— , and Coauthors, 2018: Different response of surface temperature and air temperature to deforestation in climate models, Earth Syst. Dyn. Discuss., https://doi.org/10.5194/esd-2018-66.

Xiao, Z., S. Liang, J. Wang, P. Chen, X. Yin, L. Zhang, and J. Song, 2014: Use of general regression neural networks for generating the GLASS leaf area index product from time-series MODIS surface reflectance. IEEE Trans. Geosci. Remote, 52, 209-223, https://doi.org/10.1109/TGRS.2013.2237780.

Xu, Z., R. Mahmood, Z. Yang, C. Fu, and H. Su, 2015: Investigating diurnal and seasonal climatic response to land use and land cover change over monsoon Asia with the Community Earth System Model. J. Geophys. Res. Atmos., 120, 1137-1152, https://doi.org/10.1002/2014JD022479.

Yang, K., J. He, W. Tang, J. Qin, and C. C. K. Cheng, 2010: On downward shortwave and longwave radiations over high altitude regions: Observation and modeling in the Tibetan Plateau. Agric. For. Meteor., 150, 38-46, https://doi.org/10.1016/ j.agrformet.2009.08.004.

Zhang, M., and Coauthors, 2014: Response of surface air temperature to small-scale land clearing across latitudes. Environ. Res. Lett., 9, 034002, https://doi.org/10.1088/1748-9326/9/3/ 034002.

Zhao, K., and R. B. Jackson, 2014: Biophysical forcings of land-use changes from potential forestry activities in North America. Ecol. Monogr., 84, 329-353, https://doi.org/10.1890/12-1705.1. 